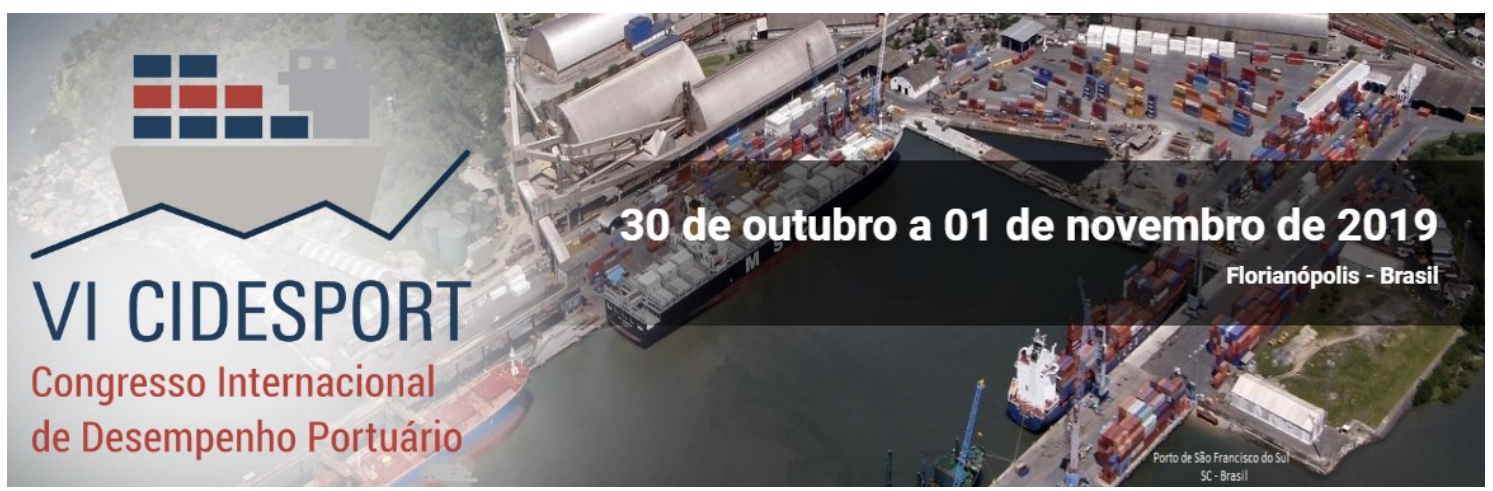

\title{
APROVEITAMENTO DO MATERIAL DRAGADO: UMA ANÁLISE PARA O CONTEXTO BRASILEIRO
}

Gabriel Kvassay

Universidade Federal do Rio de Janeiro

Daniele Moraes Electo de Paiva

Universidade Federal do Rio de Janeiro

Gardenio Diogo Pimentel da Silva Universidade Federal do Rio de Janeiro

Guilherme de Moura Haguenauer Universidade Federal do Rio de Janeiro

Marcos de Freitas

Universidade Federal do Rio de Janeiro

Resumo: O Programa Nacional de Dragagem (PND I), lançado em 2007, teve como resultado a remoção de aproximadamente 73 milhões de metros cúbicos de sedimentos. A segunda edição, em 2012, tinha como previsão 44,5 milhões de metros cúbicos de sedimentos dragados do canal de acesso de quatro portos. O objetivo geral da presente pesquisa é apresentar as principais estratégias, conceitos e aspectos legais destinados a subsidiar a tomada de decisão do gestor público quanto ao uso de material dragado proveniente de obras nos canais de acesso aos portos brasileiros, por meio de soluções técnico-econômicas e ambientalmente viáveis. Nesta análise, são apresentadas experiências internacionais de aproveitamento de material dragado e suas respectivas viabilidades de implementação no âmbito brasileiro. Este estudo demonstra que o uso de sedimentos de dragagem para fins de destinação como engordamento de praias, aterramento hidráulico de terreno e destinação oceânica são práticas usuais em todos os aspectos analisados. Incluindo-se, igualmente, a tipologia de aproveitamento, sua aplicabilidade e peculiaridades quanto ao planejamento no Brasil. Finalmente, é apresentada uma árvore de decisão que almeja subsidiar a tomada de decisão do gestor público quanto ao uso de material dragado. A análise apresentada possibilitará embasar o gestor público em sua tomada de decisão quanto às formas mais adequadas e sustentáveis de aproveitamento do material dragado durante obras de dragagem nos portos brasileiros. Como recomendação final, propõese a formulação de um plano de viabilidade associado ao PND para sugerir caminhos e alternativas de aproveitamento do material dragado, com potencial de gerar renda e contribuir para a gestão ambiental adequada nos portos brasileiros em longo prazo.

Palavras-chaves: aproveitamento de sedimentos. Dragagem. Engordamento de praias. CONAMA 454/2012.

* A revisão gramatical, ortográfica, ABNT ou APA foi realizada pelos autores. 


\section{CIDESPORT/2019}

\section{Congresso Internacional}

de Desempenho Portuário

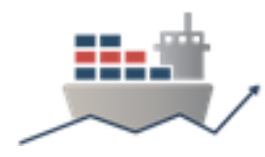

\section{INTRODUÇÃO}

O desenvolvimento da infraestrutura portuária, incluindo as obras de dragagem dos seus canais de acesso, conta com investimentos orçamentários anuais do Governo Federal e, para tanto, requer, entre outras prioridades, a realização de estudos capazes de orientar e dar suporte às atividades previstas no Programa Nacional de Dragagem (PND). Segundo dados da Secretaria Nacional de Portos, o PND I, lançado em 2007, teve como resultado a remoção de aproximadamente 73 milhões de metros cúbicos de sedimentos em 16 portos. Em 2012, O PND II foi lançado, com previsão de 44,5 milhões de metros cúbicos de sedimentos dragados do canal de acesso de quatro portos.

Os benefícios da dragagem vão além daquele a que se destina, qual seja, o aumento do calado. Segundo SIMÕES (2009), os sedimentos retirados podem ser utilizados na alimentação de praias e construção de diques e dunas para a proteção costeira; a areia e pedregulhos retirados podem ser utilizados na construção civil, gerando impacto menor no meio ambiente se comparado à retirada de material de mesmo tipo em exploração em terra; e, ainda, pode contribuir com o controle da eutrofização.

Relativo ao aproveitamento dos sedimentos dragados, a CONAMA 454 de 2012, que estabelece as diretrizes gerais e os procedimentos referenciais para o gerenciamento do material a ser dragado em águas sob jurisdição nacional, traz em seu Art. 15 o seguinte: "O empreendedor deverá considerar, previamente à decisão sobre a disposição, a possibilidade da utilização benéfica do material dragado, de acordo com sua caracterização e classificação, bem como a avaliação ambiental e a análise da viabilidade econômica e operacional das opções de disposição, atendidas as regulamentações específicas e pertinentes".

O aumento do fluxo de comercialização de produtos diversos de forma globalizada tem demandado maior desempenho do setor marítimo a cada ano, com aumento das escalas dos navios e, por consequência, aumento dos calados. Seguindo esta lógica, obras de dragagem são necessárias para atender à frota, tanto no aprofundamento quanto na manutenção de canais de acesso aos portos, e os sedimentos dragados requerem destinação correta, seja ela na disposição final ou com o seu aproveitamento.

Apesar do aproveitamento ser pensado como a melhor opção, eliminando-se assim, a deposição em águas marítimas, há limitações de cunho legal e técnico que devem ser consultadas para que não se crie um passivo ambiental com consequências diretas ao meio em que este está inserido.

A preocupação com o material contaminado apresenta-se como uma constante ao se considerar o uso de material dragado. De forma geral, a maior presença de partículas mais finas e alto teor de matéria orgânica no sedimento implicam em maior potencial de contaminação (CEDA, 2010). No entanto, sabe-se que uma pequena porção deste material geralmente apresenta algum tipo de contaminação. No Estados Unidos, aproximadamente 200 milhões de metros cúbicos são dragados por ano, dos quais, cerca de 2.3 a 9 milhões são contaminados (JAGLAL et al., 2017). No Porto de Rotterdam, na Holanda, são dragados 20 milhões de metros cúbicos ao ano, dos quais mais de $90 \%$ não são contaminados (VELLINGA \& EISMA, 2005).

O objetivo geral do presente trabalho é apresentar as principais estratégias, conceitos e aspectos legais destinados a subsidiar a tomada de decisão do gestor público quanto ao uso de material dragado, proveniente de obras nos canais de acesso aos portos brasileiros, por meio de soluções técnico-econômicas e ambientais 


\section{CIDESPORT/2019}

\section{Congresso Internacional}

de Desempenho Portuário

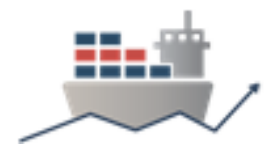

viáveis. Além disso, busca-se apontar as alternativas viáveis para o aproveitamento do material dragado no contexto brasileiro, tomando como base as boas práticas internacionais e suas compatibilidades com a legislação brasileira vigente.

\section{METODOLOGIA}

Como processo metodológico para as possibilidades de uso do material dragado, foi utilizada a pesquisa do tipo exploratória, por meio de entrevistas e pesquisas bibliográficas. As alternativas de aproveitamento do sedimento dragado foram divididas baseando-se o proposto pela legislação ambiental CONAMA 454/12 em Obras de Engenharia, Construção Civil e Indústria. A primeira categoria inclui projetos de proteção costeira, estabilização da linha de margens de rios e controle de erosão, bermas submersas e emersas. O segundo grupo consiste de obras de aterro, blocos e tijolos, aterro para base de estradas e superfícies pavimentadas, e agricultura.

Para cada subitem supracitado, foram estabelecidos tópicos, buscando-se entendimento da técnica de aproveitamento e identificação da possibilidade de uso da mesma no contexto brasileiro, conforme a seguir:

- Critérios técnicos, operacionais, legais e ambientais relevantes, e que se aplicam de forma geral à técnica de aproveitamento apresentada.

- Exemplos de aplicação de casos nacionais e internacionais das técnicas de aproveitamento do sedimento dragado apresentadas, visando possível espelhamento nas operações de dragagem no Brasil.

- Análise crítica fundamentada na expertise de profissionais do ramo, e voltada à viabilidade técnica, ambiental, legal, e econômica das técnicas de aproveitamento apresentadas.

Após descrição das diversas possibilidades de uso do material dragado, são apresentadas informações complementares referentes à adequação dos sedimentos dragados aos respectivos tipos de uso. 
VI CIDESPORT/2019

Congresso Internacional

de Desempenho Portuário

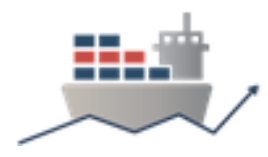

Por fim, é apresentada, por meio de uma árvore de decisão

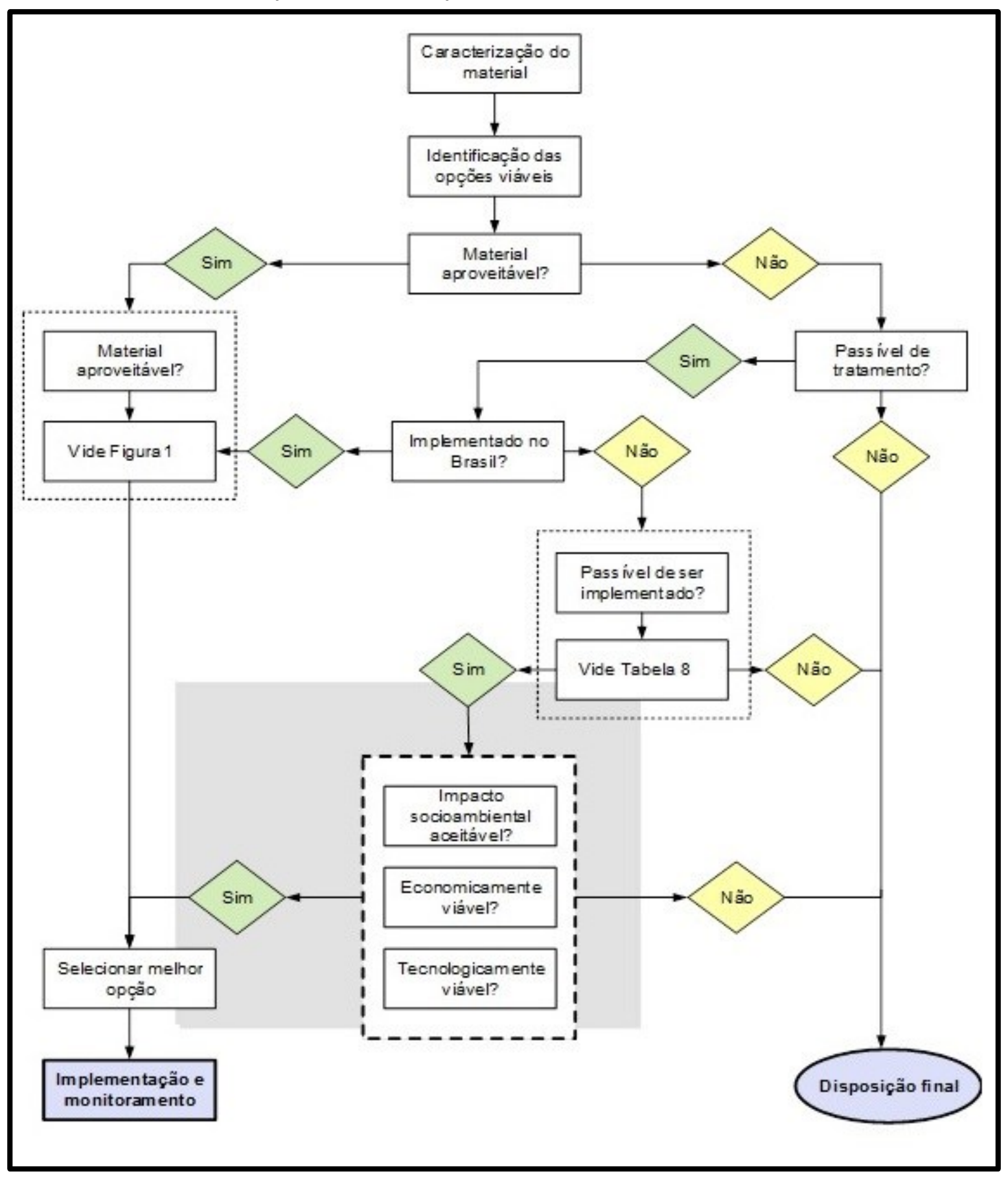

), uma análise de caminho crítico das possibilidades de aproveitamento do material dragado com o intuito de auxiliar o gestor público no seu processo decisório.

\section{DESENVOLVIMENTO}

Nesta seção serão apresentadas as diversas possibilidades de aproveitamento do material dragado, sendo estas classificadas por tipo de utilização, a saber: Obras de Engenharia, Construção Civil e Indústria, e Agricultura. 


\section{CIDESPORT/2019}

\section{Congresso Internacional}

de Desempenho Portuário

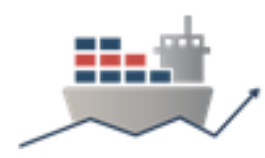

\subsection{Obras de engenharia}

\subsubsection{Engordamento de praias}

Para a criação e melhoria de terreno, a recomposição e o engordamento artificial de praias, devem ser considerados alguns critérios relativos ao material dragado e a sua disposição. Abaixo, foram enumerados os principais deles (MDE 2017):

- O material dragado deve ser analisado em laboratório e atestado como não contaminado ou de baixo risco para saúde humana;

- A análise granulométrica do material a ser dragado e a avaliação do local de disposição devem ser realizadas. O tamanho de grão do material dragado deve ser igual ou maior do que o do material existente no local a ser engordado; alternativamente, análises adicionais das características do sedimento devem ser realizadas para garantir a compatibilidade com as condições do local de destinação;

- Durante o processo de engordamento / recomposição de praia por meio de uma obra de dragagem, recomenda-se que a mistura de componentes minerais deste material seja equilibrada em termos de concentração, ou seja, nem tão líquida e nem tão concentrada, para que se alcance a estrutura almejada sem que ocorra o desmanche da mesma ou o entupimento da linha, respectivamente.

- Medidas de controle, como quebra-mares, esporões ou estruturas similares, devem ser usadas para controlar o movimento dos sedimentos;

- O material dragado deve estar relativamente livre de material orgânico, detritos flutuantes e outros objetos, e não deve causar impactos adversos aos canais de navegação existentes, às correntes de longo curso, às propriedades adjacentes e aos padrões de desova, viveiro ou migração de peixes; e

- Um estudo prévio comparativo deve ser realizado sobre o custo de transporte de grandes volumes de material dragado, considerando-se o local de destino e a rota utilizada no deslocamento.

\section{* Engordamento da Praia de Copacabana, RJ}

A Praia de Copacabana tem cerca de 3,7 km de extensão e é uma das maiores atrações naturais da cidade do Rio de Janeiro. As primeiras construções relevantes desse local datam da década de 1920, porém a partir da década de 1940 o ritmo de edificações aumentou de tal ordem que Copacabana tornou-se uma das áreas de maior densidade urbana da cidade.

Após estudos e levantamentos realizados em Copacabana relativos à inclinação da praia, análise granulométrica da areia, marés e ondulação locais, e ventos, concluiu-se que Copacabana era uma praia em equilíbrio, isto é, não era alimentada por fonte importante de material arenoso externo. Além disso, a praia atingira a configuração que melhor se ajustava às características dos agentes atuantes, particularmente, a ondulação.

Dessa maneira, foram aplicados dois métodos de engordamento: as cotas positivas (a ser executado por dragas de sucção e recalque); e as cotas negativas (por alimentação submarina, com draga autotransportadora). A primeira opção consistiu na alimentação artificial de areia retirada de um depósito (no caso, a enseada 


\section{CIDESPORT/2019}

\section{Congresso Internacional}

de Desempenho Portuário

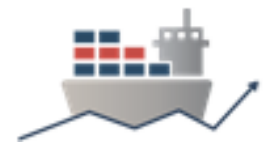

de Botafogo) e na subsequente disposição na praia. Esta operação seria realizada por duas dragas de sucção e recalque, entre os níveis de baixamar e preamar.

Já as obras realizadas a cotas negativas consistiram em um processo de alimentação da praia por meio da retirada de areia de um banco já existente (no caso, perto de Niterói) e posterior depósito em fundos submarinos, ou seja, a cotas negativas em relação ao nível do mar. Este processo seria executado por uma draga autotransportadora. A diferença para a primeira opção é que a deposição da areia é feita exclusivamente pela ação das ondas nos depósitos formados pela draga. Dois pontos desfavoráveis a esta opção foram a instalação de recalque, considerada de grande complexidade e ineditismo até então, e o ritmo de alargamento da praia, que seria mais lento e, por depender exclusivamente da ação das ondas, com maior grau de imprevisibilidade.

Ao final das obras, concluiu-se que os resultados alcançados no engordamento revelaram-se bastante favoráveis no que tange ao processo a cotas positivas. Por esta razão, foi adicionado um volume de $500.000 \mathrm{~m}^{3}$ aos 2 milhões de $\mathrm{m}^{3}$ inicialmente contratados por este método. Por outro lado, o alargamento a cotas negativas revelouse bom coadjuvante no resultado de engordamento. Ao final do projeto, o alargamento médio realizado foi de 80 metros e o volume total de areia utilizado no engordamento foi de $3.500 .000 \mathrm{~m}^{3}$. A Figura 1 mostra diferentes aspectos da Praia de Copacabana antes e após o engordamento. Antes (à esquerda), nota-se a pista única de trânsito situada junto aos edifícios da orla, e vista atual (à direita), em que se nota a pista dupla da Avenida Atlântica e a faixa de areia mais larga.

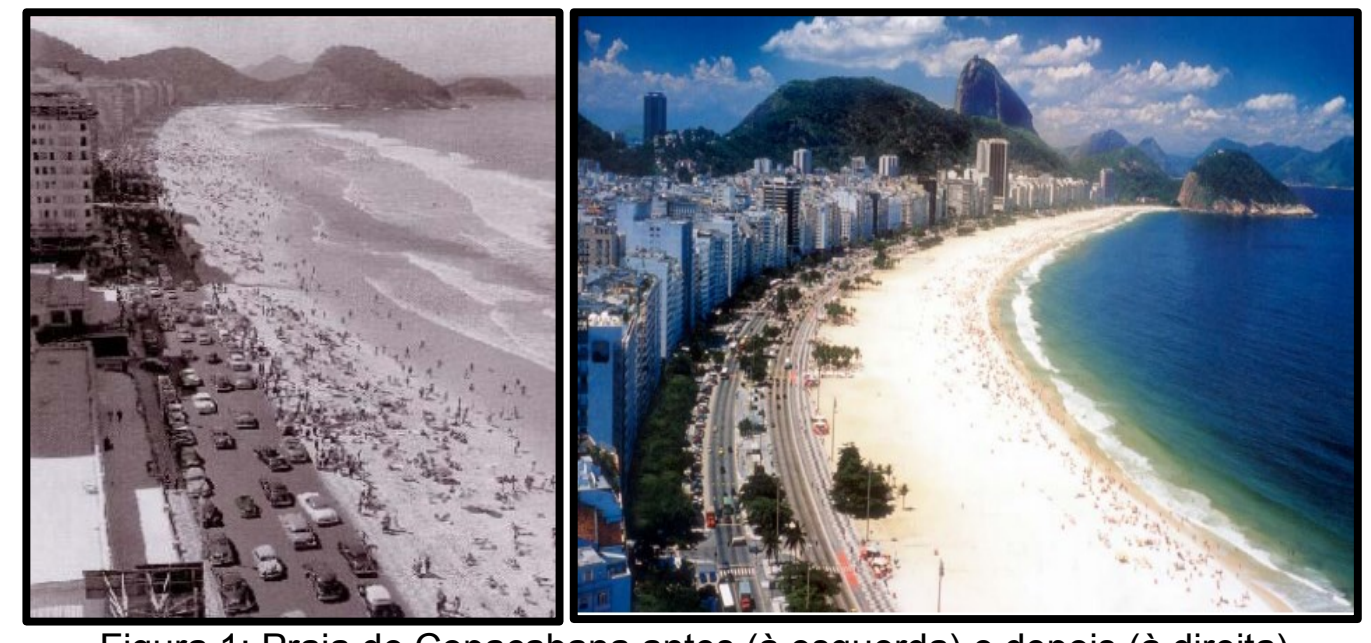

Figura 1: Praia de Copacabana antes (à esquerda) e depois (à direita) do engordamento artificial.

Fonte: Oliveira, 2012.

\subsubsection{Bermas}

Algumas restrições se aplicam neste tipo de construção, tais como a qualidade da areia utilizada nas bermas de alimentação próximas à costa, que usualmente estão em águas rasas, e a granulometria do material utilizado deve ser tal que proporcione estabilidade à berma em questão (US ARMY, 1990).

Para a utilização em bermas offshore, o material pode ser tanto leve (areia), para sustentar a energia das ondas, como pesado (cascalhos, rochas e tubos cheios de sedimentos), com intuito de suportar a força de ondas maiores. Todavia, a última opção é considerada mais aconselhável (BURT, 1996). 


\section{CIDESPORT/2019}

\section{Congresso Internacional}

de Desempenho Portuário

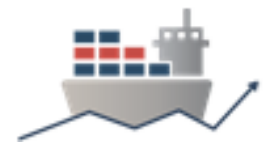

Segundo Harrington \& Smith (2013), a areia de granulometria fina à média é considerada como mais apropriada à construção de bermas de encosta, ou emersas, enquanto que o material de granulometria grossa é melhor aplicado na construção de bermas estáveis, como as offshore, para absorver a energia das ondas.

\section{* Baía de São Francisco, Califórnia}

O material dragado do canal de navegação da Baía de São Francisco, na Califórnia, foi alocado em uma área próxima à costa para mitigar erosão intensa ao longo da praia (Ocean Beach). O processo de erosão ameaça estruturas públicas, bem como o uso recreativo da praia de maneira segura. Foram utilizados como recurso, a atenuação de ondas e a suplementação de sedimentos. O USACE (Corpo de Engenheiros do Exército dos Estados Unidos) determinou em projeto, a disposição anual de aproximadamente $230,000 \mathrm{~m}^{3}$ de areia. Estudos indicaram que aproximadamente metade dos sedimentos que foram alocados durante o período de dois anos e meio permaneceram no local. A Figura 2 ilustra o local próximo à costa onde a berma foi construída (SF - 8).

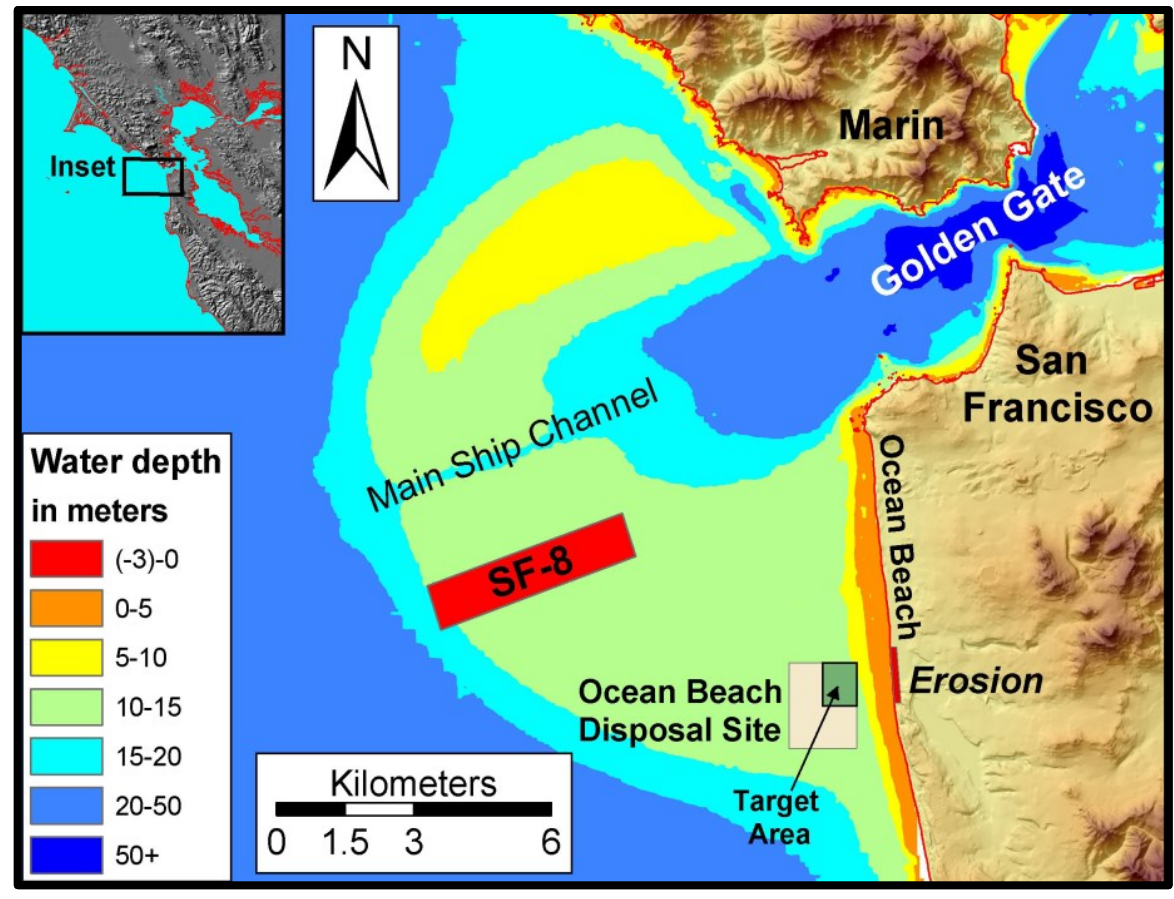

Figura 2: Berma construída próxima à Baía de São Francisco. Fonte: Barnard et al., 2009.

* Fort Myers e Perdido Key, Florida -USA, 2009 e 2012, respectivamente

Nesses locais, sedimentos de obras de dragagem de manutenção em áreas próximas foram utilizados para alimentar bermas próximas à costa. A constituição da berma da praia de Fort Myers Beach era de $16 \%$ de grãos finos ( $<0.063 \mathrm{~mm}$ ). Neste local, buscou-se alimentar a berma proporcionando condições para que os finos fossem transportados para longe da costa, ao passo que sedimentos mais grossos fossem transportados para nutrir a praia. Em Perdido Key, a berma próxima à arrebentação tinha como objetivo mobilizar o sedimento de forma rápida para alimentar as praias locais. Ambas as áreas de estudo e aplicação do método foram consideradas de sucesso. A Figura 3 ilustra as duas regiões de estudo. Perdido Key 


\section{CIDESPORT/2019}

Congresso Internacional

de Desempenho Portuário

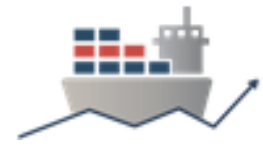

está localizada na porção mais ao norte do Estado da Flórida, e Fort Myers Beach está localizada na parte centro oeste, mais ao sul.

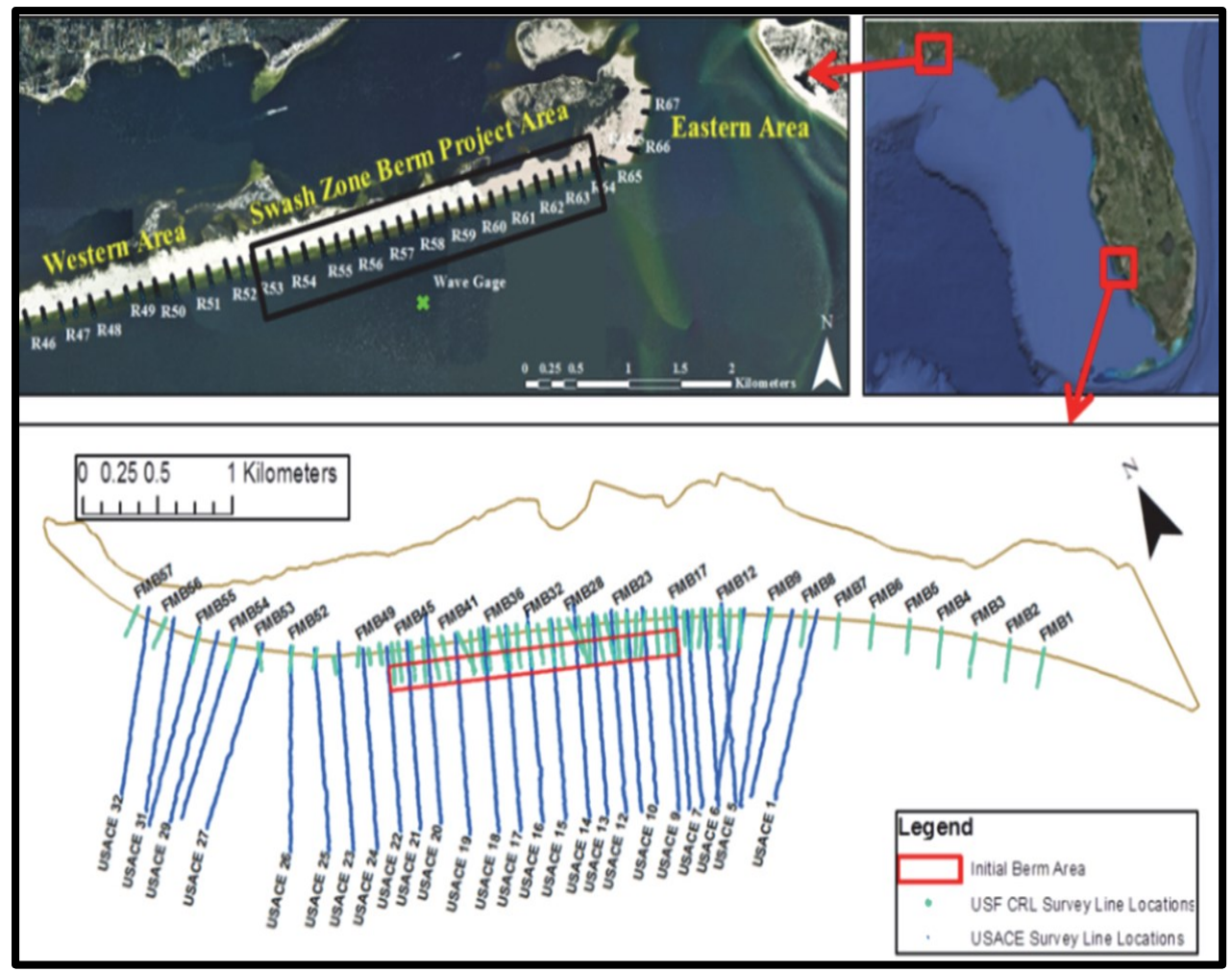

Figura 3: Localização das áreas de estudo.

Fonte: Brutsché et al, 2015.

\section{* Bermas emersas}

As bermas emersas aqui abordadas constituem em áreas para o desenvolvimento e manutenção de habitats animais e produção vegetal. $O$ material de dragagem usado como substrato no desenvolvimento de habitat é considerado uma das formas mais comuns e importantes de usos benéficos de dragado.

Há quatro tipos de habitats apropriados para o uso de sedimentos de dragagem, quais sejam de áreas alagadas (wetlands), de áreas de planalto, habitats aquáticos, e de ilhas. Há diversas alternativas de desenvolvimento para os variados habitats. É necessário o conhecimento específico das várias comunidades biológicas na área em questão para o processo de aplicação desta tecnologia na delimitação de áreas de interesse.

\section{* Ilha de Jetty, Everett, 1990}

Trabalhando em cooperação, o USACE (Corpo de Engenheiros do Exército dos Estados Unidos), o distrito de Seattle, e o Porto de Everett, no estado de Washington, usaram material dragado proveniente de um projeto de longo prazo de dragagem de manutenção. O material foi utilizado na alimentação de praias, por meio de bermas protetivas que permitissem a criação de habitats em lagoas e sapais na costa entre 1990 e 1998. A proximidade da ilha de Jetty com a área dragada tornou o projeto menos oneroso em relação ao descarte em alto mar. Monitoramentos físicos feitos em 


\section{CIDESPORT/2019}

Congresso Internacional

de Desempenho Portuário

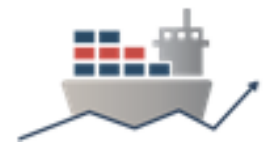

1999 mostraram acurácia de estudos relativos à taxa de erosão previamente feitos, e monitoramentos biológicos concluíram que o desenvolvimento de sapais superou as expectativas, justificando, portanto, a alimentação das praias. A Figura 4 ilustra a área dedicada.

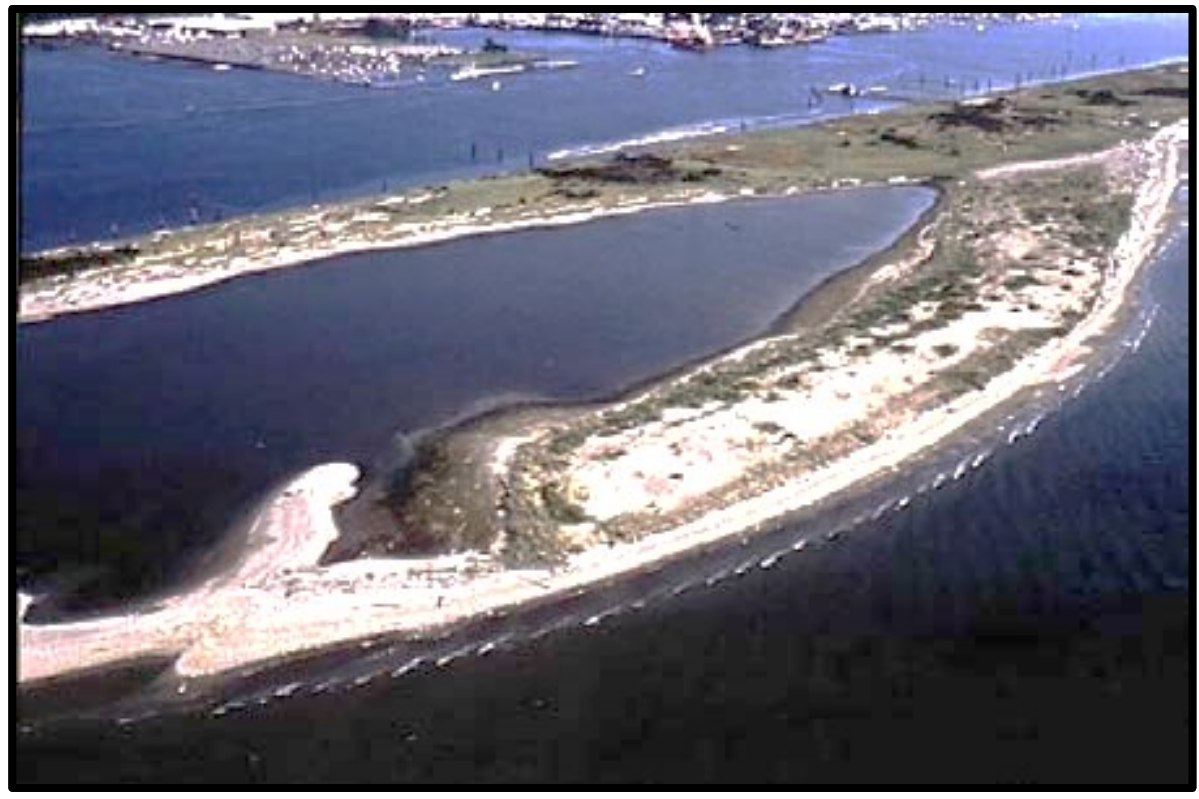

Figura 4: Área na llha de Jetty onde berma foi implantada, com objetivo de revitalização biológica.

Fonte: Witzgall, 2006.

\subsection{Construção Civil e Indústria}

Além do uso na recuperação de áreas costeiras, por meio do engordamento de praias e bermas offshore, os sedimentos dragados de portos marinhos estão sendo pesquisados e utilizados como insumo para a indústria da construção civil. Ressaltase, todavia, que a aplicação direta do material dragado é inviabilizada devido a presença de sais nos sedimentos, o que, consequentemente, implica na necessidade de tratamento para que estes atinjam as propriedades mecânicas desejadas.

\subsubsection{Aterro}

Semelhante à utilização dos sedimentos finos na recomposição de praias, os materiais dragados podem ser usados para aterros e criação de faixas terrestres fora do ambiente costeiro. Dependendo do tipo de terreno e finalidade do aterro (fundação ou somente aterro), pode haver necessidade de tratamento do material. Além disso, ambos sedimentos finos e grossos podem ser aproveitados como aterro, porém a resistência do material no solo pode ser baixa, servindo, idealmente, para preenchimento de terreno, tais como parques e outros espaços físicos cuja carga não seja elevada.

É recomendado que haja um tipo de secagem do material para facilitar sua consolidação no terreno. Geralmente, para uso como aterro de fundação de obras que necessitam de maior carga sobre o solo, os materiais não são adequados e devem ser tratados (secagem e dessalinização) e misturados com outros componentes como areia, seixo, cimentos, entre outros. 


\section{CIDESPORT/2019}

\section{Congresso Internacional}

de Desempenho Portuário

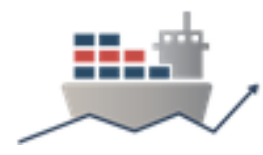

O uso de sedimentos para o preenchimento de terrenos não requer extrema complexidade técnica. De forma geral, podem ser consideradas as seguintes recomendações:

- Os sedimentos não devem conter substâncias consideradas tóxicas, em concentrações tais que possam apresentar riscos à saúde humana de acordo com as normas brasileiras;

- As concentrações de compostos orgânicos na mistura de sedimentos devem ser baixas;

- Os sedimentos devem apresentar características físico-químicas semelhantes às do local a ser preenchido;

- Sabendo-se que os sedimentos de dragagem normalmente não possuem boas características mecânicas e demoram mais para consolidar, é necessário que se conheça a capacidade de carga do sedimento/solo, evitando o preenchimento para construções sem a realização dos devidos testes descritos na NBR 6122/2010; e

- O material "ideal" para este tipo de aproveitamento é areia com baixo conteúdo de água e com granulometria entre 0,1-0,6 mm. Areia com cascalhos também pode ser facilmente aproveitada (BURT, 1996).

\section{* Programa de Revitalização e Recuperação Ambiental do Canal do Fundão - 2012.}

A revitalização do canal da ilha do Fundão - RJ (Figura 5) foi um projeto de recuperação ambiental da Secretaria de Estado do Ambiente (SEA), e é considerado uma das maiores dragagens de material contaminado do mundo. Várias dragas de tamanhos diversos foram utilizadas no processo de aprofundamento do canal. No processo, mais de 3 milhões de $\mathrm{m}^{3}$ de sedimentos contaminados foram dragados ao longo de $7 \mathrm{~km}$ do canal. A areia retirada foi aproveitada em diversas obras.

Para o material contaminado, foi adotada uma tecnologia moderna para encapsular o material retirado em estruturas de geotêxtil (bolsas enormes de malha sintética que podem chegar a 80 metros de comprimento), conforme ilustrado pela Figura 5. A água descontaminada retornou a Baía de Guanabara. As estruturas formadas pelo geotêxtil serviram também para estabilizar o solo, permitindo o seu aterramento e o plantio de mais de 500 mil mudas de plantas, com a revitalização de $400 \mathrm{mil} \mathrm{m}^{2}$ de áreas degradadas e a recuperação de mais de $33 \mathrm{~km}^{2}$ de manguezais. O ecossistema do Canal do Fundão ganhou vida nova: aves que não eram vistas há 20 anos retornaram à região (INEA 2012). 


\section{CIDESPORT/2019}

Congresso Internacional

de Desempenho Portuário

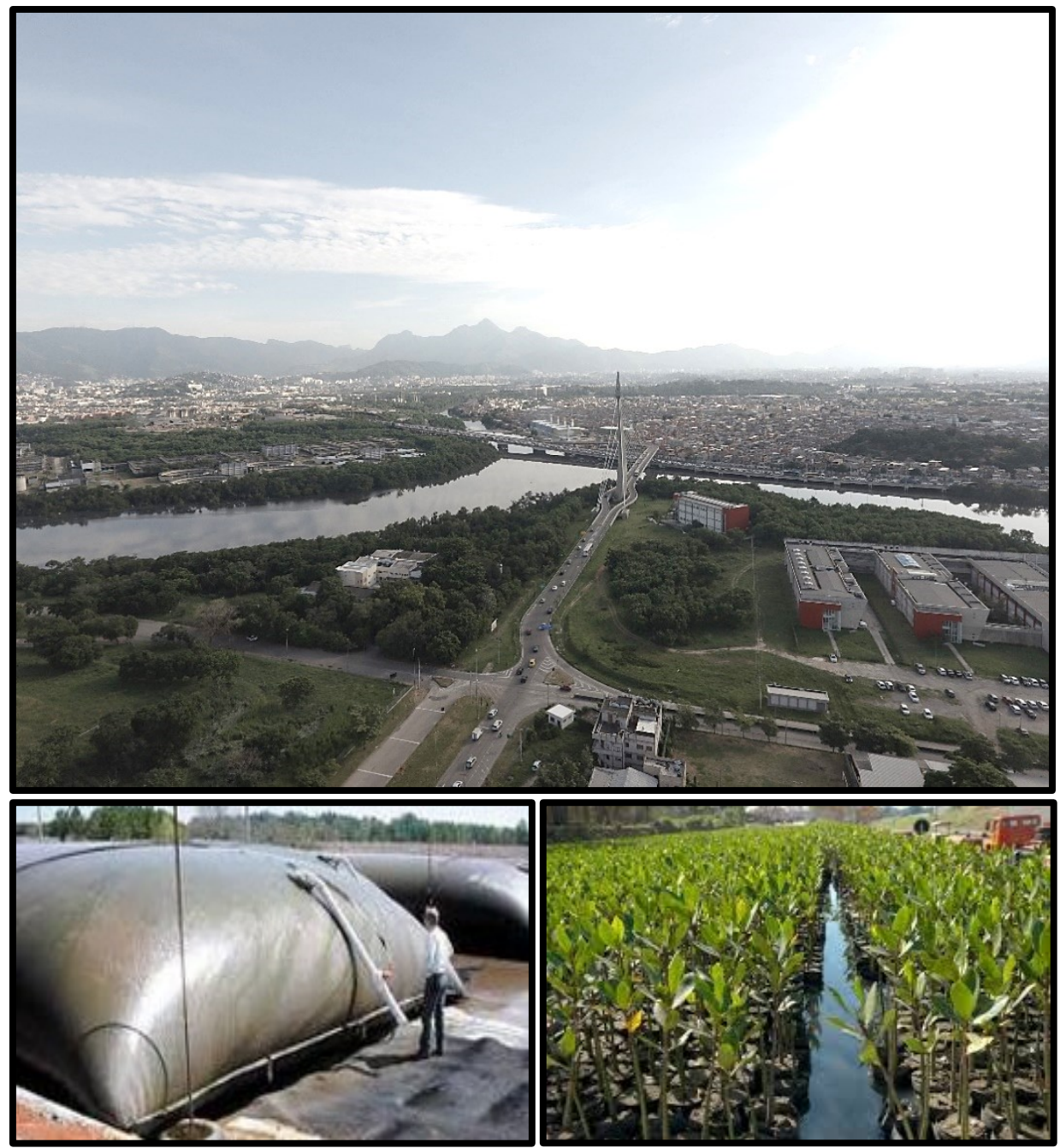

Figura 5: Projeto de recuperação e revitalização do Canal do Fundão - RJ. Fonte: Escola Politécnica UFRJ, 2012.

\section{* Aterro hidráulico da Maré: Vila do João - Projeto Rio - 1980.}

Em junho de 1979, o Ministério do Interior anunciou um enorme aterro a ser realizado pelo Departamento Nacional de Obras de Saneamento (DNOS) que criaria mais de 2.300 novos hectares de terras na borda noroeste da Baía de Guanabara RJ. Estas novas terras, supostamente suficientes para abrigar 1,2 milhões de pessoas (na época, um quarto da população do Rio de Janeiro) forneceriam espaço para maior infraestrutura de transporte, indústria e habitação na requisitada área entre o Centro, o Aeroporto Internacional e a Universidade Federal da cidade.

Este projeto fazia parte de uma política a favor da urbanização da infraestrutura no local (JONES, 2017). Em março de 1980, se iniciaram as obras do aterro hidráulico da Ilha do Pinheiro, que escapara ao aterro da Cidade Universitária, mas que acabou incorporando o continente. Foram, assim, aterrados 69 hectares da Baía de Guanabara pelo DNOS (MUSEU DA MARÉ, 2010), Figura 6. 
VI CIDESPORT/2019

Congresso Internacional

de Desempenho Portuário

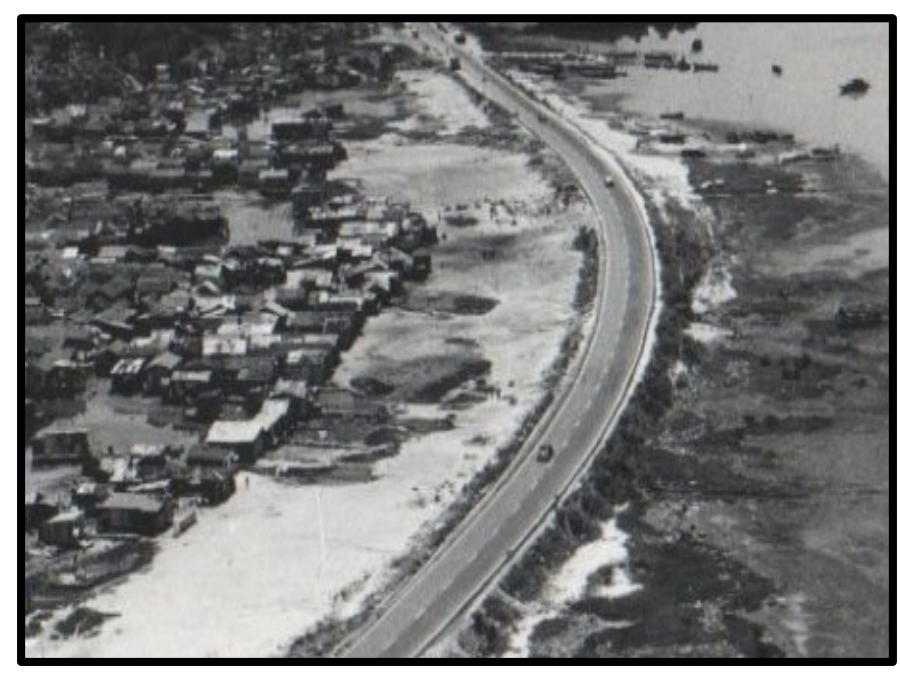

Figura 6: Aterro da Maré na década de 1970.

Fonte: Araújo, 2012.

\subsubsection{Blocos e tijolos}

A utilização dos sedimentos como insumo na fabricação de blocos de concreto e tijolos para pavimentos ou construção de moradias é também uma alternativa de aproveitamento viável. O tratamento do material dragado para esta finalidade é imprescindível para que o sedimento adquira as características adequadas à construção civil, o que imprime grau de complexidade à técnica em questão. No entanto, esta forma de aproveitamento engloba vantagens desde a valorização dos sedimentos no produto final, à possibilidade de aproveitamento de materiais mais argilosos, normalmente descartados, e sedimentos contaminados, pois os blocos passam por tratamento térmico que estabiliza os materiais.

A destinação de sedimentos dragados para fabricação de blocos para pavimentação ou tijolos para construção civil vem sendo estudada e proposta tanto em escala industrial, como na Alemanha e Tunísia, como em escala laboratorial, a exemplo dos Estados Unidos.

Os sedimentos destinados à fabricação de blocos e tijolos devem passar impreterivelmente por processo de caracterização, de modo a conhecer sua granulometria, presença de contaminantes e matéria orgânica, concentração de sais e conteúdo de água, conforme especificações a seguir:

- Análise em laboratório para determinar se o material apresenta algum risco à saúde humana;

- Análise granulométrica do material, visando melhor destinação e compatibilidade com local de preenchimento ou insumo para fabricação de blocos;

- Conteúdo de areia não deve superar 30\% (blocos feitos de material argiloso);

- Teor de água deve ficar em torno de $40 \%$ e baixa salinidade;

- Mistura com outros compostos (cimento, areia, lima, cal, entre outros) para aquisição de propriedades mecânicas e tratamento; e

- Para fabricação de blocos e tijolos, os produtos devem seguir as normas brasileiras como NBR 10005:2004 (lixiviação de material); NBR 100004: 2004 classificação dos resíduos sólidos; NBR 9.781:2013 Peças de concreto para pavimentação (Especificação e métodos de ensaio); NBR 10833:2012 (Fabricação de tijolo e bloco de solo-cimento com utilização de prensa manual 


\section{CIDESPORT/2019}

Congresso Internacional

de Desempenho Portuário

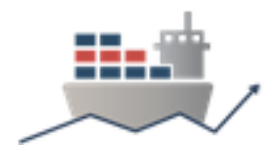

ou hidráulica - Procedimento).

\section{* Estados Unidos - 2012.}

Mezencevova et al. (2012), em seu estudo realizado nos Estados Unidos, mistura os sedimentos dragados com areia, argila e, neste caso, também com aditivos em pequena quantidade (óleo de soja para ajudar na mistura e $\mathrm{BaCO}_{3}$ ). A secagem ocorre entre 25 a $110^{\circ} \mathrm{C}$ e a queima em 900 a $1000{ }^{\circ} \mathrm{C}$. Os autores advertem que o conteúdo de água na mistura não deve ser elevado (em torno de 36\%), para evitar rachaduras e diminuição drástica no tijolo durante a primeira desidratação no forno e fabricação final, respectivamente. Os autores afirmam que os tijolos podem ser feitos com $100 \%$ de material dragado, mas que a mistura com argila e areia melhora a qualidade do produto final. Em ambos os estudos, todavia, o material dragado possui maior concentração de argila. A Figura 7 traz uma exemplificação desse tipo de produto e do processo de fabricação.

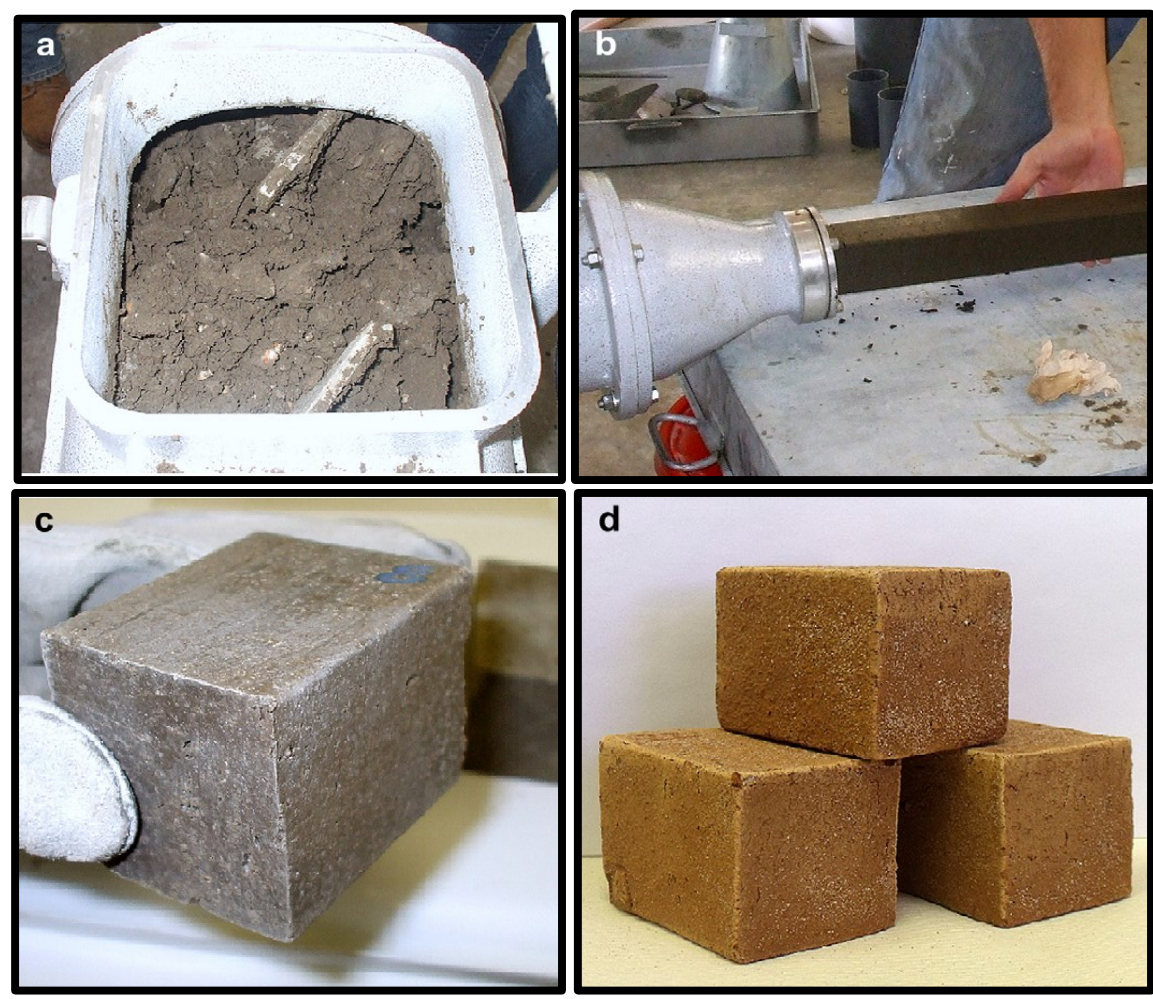

Figura 7: Material dragado misturado com sedimento (a). Formação dos tijolos (b).

Tijolo desidratado (c). Tijolo queimado (d).

Fonte: Mezencevova et al., 2012.

\section{* Tunísia - 2015.}

Said et al. (2015), em seu estudo realizado na Tunísia, teve como objetivo produzir blocos de pavimentação com sedimentos arenosos escavados do local de destinação do material dragado (Erro! Fonte de referência não encontrada.8), analisados, pré-tratados (secagem, quebra e peneirados), misturados com areia, cimento e água, moldados e, finalmente, submetidos ao processo de fabricação. 
VI CIDESPORT/2019

\section{Congresso Internacional}

de Desempenho Portuário
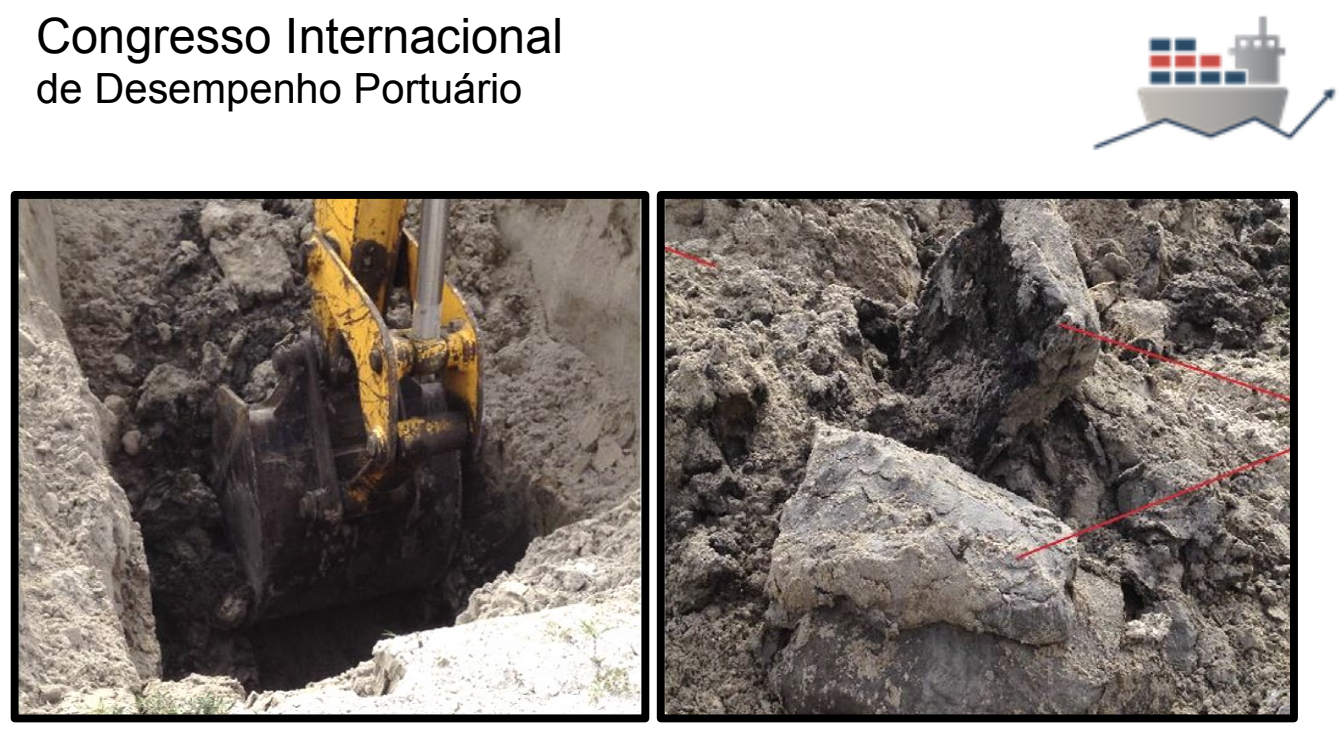

Figura 8: Escavação do local de armazenamento e aparência dos sedimentos dragados.

Fonte: Said et al, 2015.

Neste processo, todavia, não ocorre a queima dos blocos, e sim a mistura com cimento para fabricação de blocos de concreto com sedimentos dragados, conforme ilustra a Figura 99. Neste caso, materiais contaminados não podem ser usados para produção de blocos, pois não há tratamento térmico.

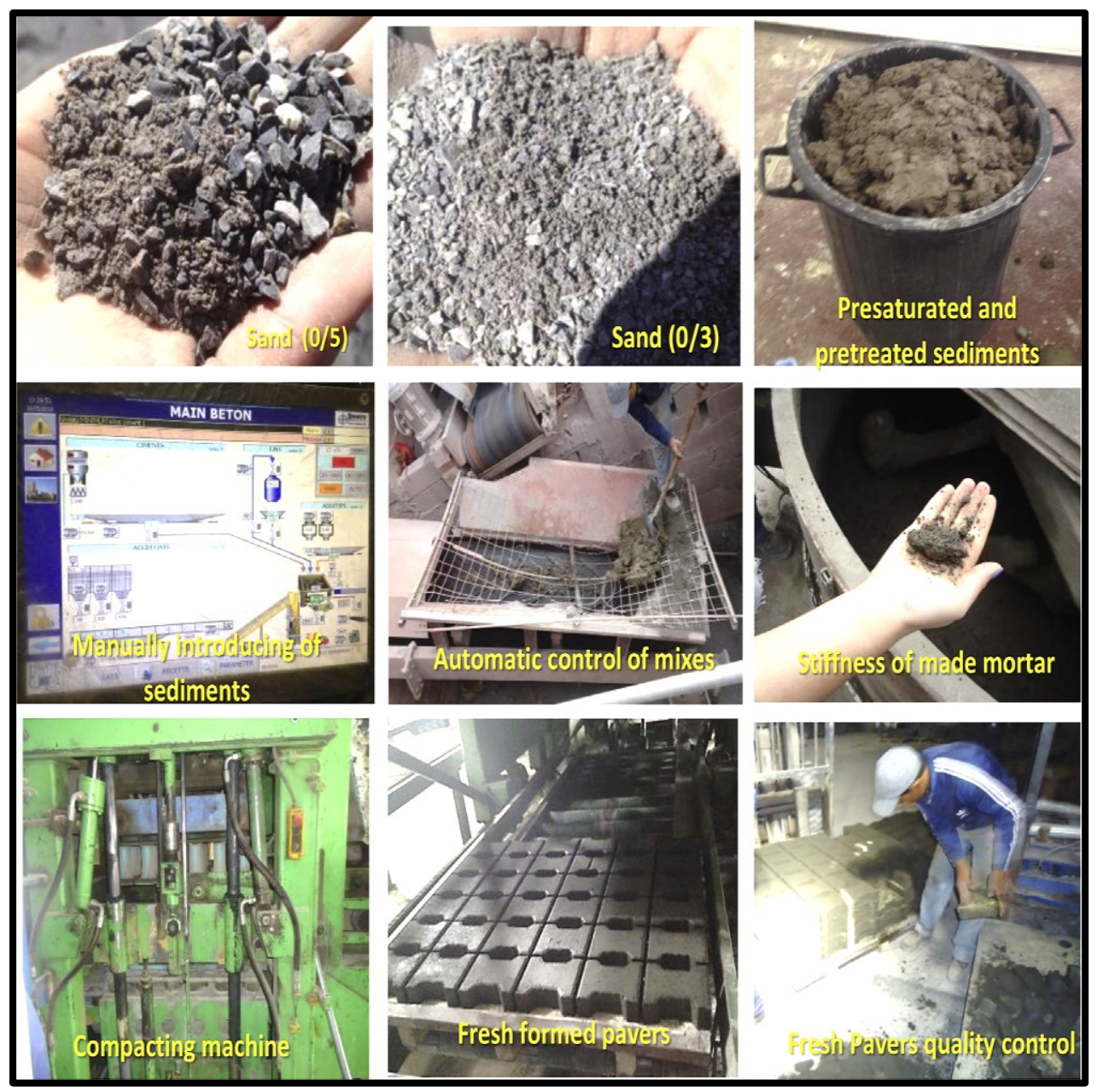

Figura 9: Processo de fabricação de blocos para pavimento com sedimentos dragados. Fonte: Said et al., 2015. 


\section{CIDESPORT/2019}

Congresso Internacional

de Desempenho Portuário

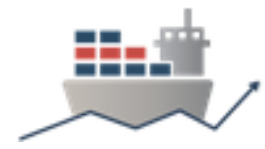

\subsubsection{Aterro para base de estradas e superfícies pavimentadas}

Semelhante ao aproveitamento dos sedimentos para aterro de preenchimento do terreno e construção civil, os materiais dragados podem ser utilizados como insumo para construção das camadas (layers) de fundação em obras de engenharia. Neste estudo é apresentado o caso de estradas e superfícies pavimentadas (caso de Dunkirk - França).

Os critérios se assemelham àqueles utilizados na construção de aterros, sabendo-se que para blocos e tijolos:

- Os sedimentos contaminados e não contaminados podem ser aproveitados, pois o pavimento impedirá o contato direto do material;

- As concentrações de compostos orgânicos na mistura de sedimentos devem ser baixas;

- Argila consolidada, areia com cascalho, areia e sedimentos não pastosos podem ser utilizados; e

- Um tratamento é requerido para retirada de sais concentrados e para que os sedimentos de dragagem adquiram boas características mecânicas.

\section{* Dunkirk - França}

O aproveitamento de sedimentos dragados como material base na fundação de superfícies pavimentadas (rodovias, estradas, entre outras) foi estudado por Siham et al. (2008), Zentar et al. (2008), Dubois et al. (2009) e Wang et al. (2016) em Dunkirk, norte da França. Exceto por Zentar et al. (2008), o qual realizou um estudo com escala real em campo, os outros autores realizaram estudos laboratoriais objetivando utilizar os sedimentos marinhos dragados como insumo de aterro de base para a construção de estradas e demais superfícies pavimentadas. O material foi transportado (Erro! Fonte de referência não encontrada.0), e armazenado em lagoas para auxiliar na desidratação natural, conforme Erro! Fonte de referência não encontrada.1.

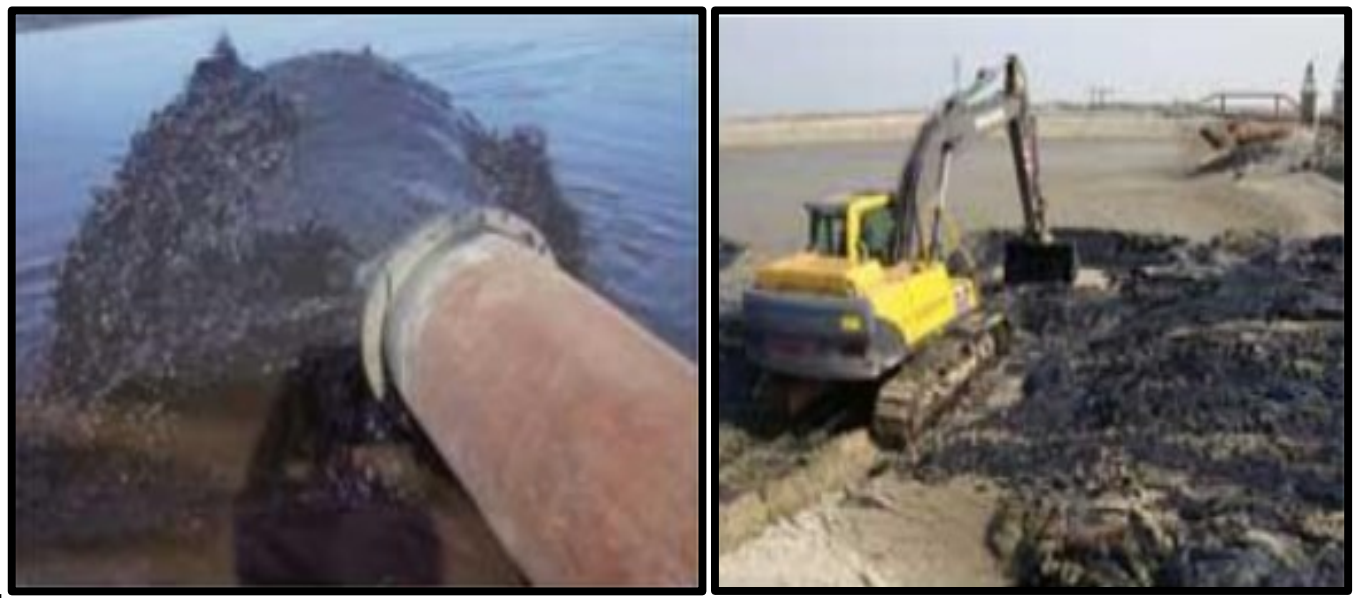

Figura 10:Transporte ao local de armazenamento e secagem natural.

Fonte: Zentar et al., 2016. 
VI CIDESPORT/2019

Congresso Internacional

de Desempenho Portuário

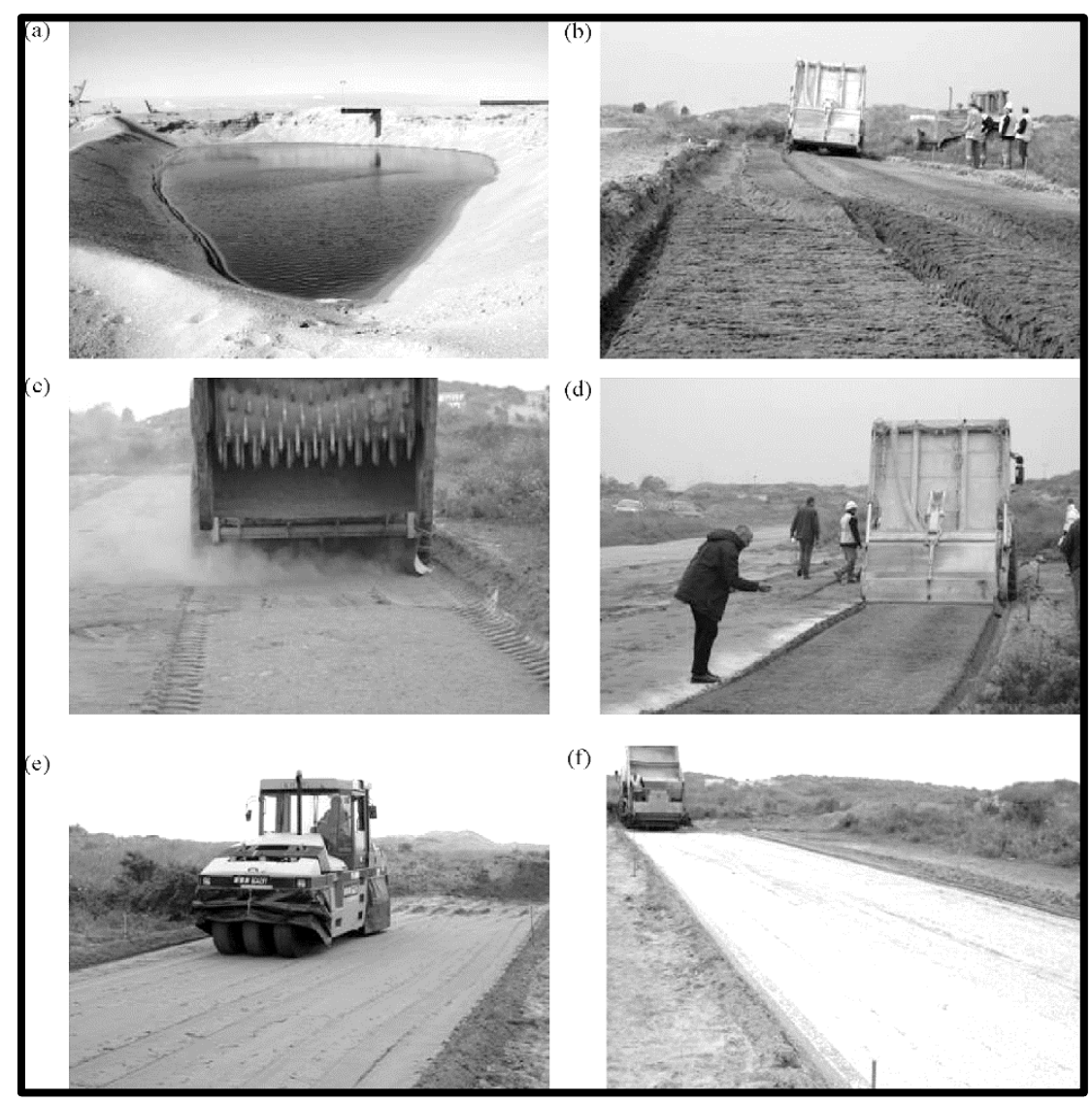

Figura 10: Armazenamento (a) e construção da superfície pavimentada.

Fonte: Zentar et al., 2008.

Os autores dos estudos afirmam que os sedimentos coletados podem ser prélavados com água doce, submetidos à floculação e à prensa hidráulica (para retirada de parte do sal) e, posteriormente, dispostos para secagem natural (para redução da salinidade via evaporação). O processo de tratamento para desidratação do material ocorre deixando-se secar por alguns dias uma camada de $200 \mathrm{~cm}$ (somente do material), e depois em camadas de $15-20 \mathrm{~cm}$ de areia e outros agregados que ajudam a homogeneizar e retirar a água do composto. Os estudos apontam bons resultados, benefícios ambientais e competitividade econômica da proposta, porém Zentar et al. (2008) sugerem que a alternativa seja melhor aplicada para estradas de baixa densidade de tráfego.

\subsubsection{Agricultura}

O uso de sedimentos de dragagem na agricultura exige forte atenção quanto à sua composição química. Contaminantes presentes podem ser incorporados pela biota terrestre, inviabilizando o consumo humano de vegetais cultivados neste solo, além da possibilidade de se contaminar águas subterrâneas e fluviais por meio da lixiviação, associada à erosão (CESAR et al, 2015).

A disposição de material dragado é indicada na correção de solos para cultivo agrícola, alterando-se as características físico-químicas do solo de forma a melhorar a disponibilidade de água e nutrientes para as plantas (GUPTA et al, 1978). Os mesmos autores citam, também, o uso de sedimento dragado na elevação da superfície do solo, como uma forma de melhoramento do processo de drenagem, e 


\section{CIDESPORT/2019}

\section{Congresso Internacional}

de Desempenho Portuário

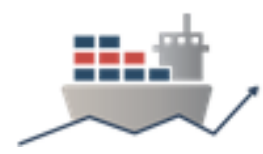

aumento da profundidade do lençol freático com consequente redução na frequência de alagamentos.

As maiores restrições quanto à aplicação de sedimentos de dragagem em solo para cultivo advêm da presença de possíveis contaminantes (e no caso de sedimentos de dragagem marítima, a presença do sal) que requerem o uso de processos para tratamento e dessalinização (CONCEIÇÃO, 2016).

Solos arenosos são geralmente menos favoráveis à produção agrícola, devido a sua característica de baixa retenção de água, capacidade de troca catiônica, textura e fertilidade (DARMODY \& DIAZ, 2017). Tais características encontram-se no sedimento de dragagem marítima, tipicamente arenoso e pobre em nutrientes, à exceção daquelas cujas origens advêm da dragagem de áreas estuarinas, como é o caso do Porto do Rio Grande - RS, em função do intenso aporte de material orgânico.

Há alternativas para a correção e aproveitamento desses sedimentos, com posterior uso como cobertura de solo para plantio. A correção pode ser obtida por meio da mistura com outros substratos, tais como cavacos de madeira, cal, gipsita, compostos orgânicos e biosólidos (ex.: lodo de estação de tratamento de esgoto e esterco), conforme sugere o Departamento de Meio Ambiente de Maryland, nos Estados Unidos, em seu "Guia de Reuso Inovador e Uso Benéfico de Material Dragado", publicado em 2017. Tal documento recomenda que testes sejam conduzidos para verificação da melhor mistura a ser usada.

O enriquecimento dos sedimentos de dragagem marítima com a adição de nutrientes, aliado à necessidade de dessalinização, podem incorrer em alto custo, inviabilizando sua utilização. Porém, existem resíduos, constantemente gerados por atividades basilares, cuja destinação final é onerosa e objeto de intensa pesquisa. Estes podem ser pensados como alternativas ao enriquecimento de solos pobres, tais como lodo tratado advindo de estações de tratamento de esgoto, e resíduos sólidos orgânicos, cujas destinações finais são principalmente o aterro sanitário.

Para que se verifiquem o uso desses substratos na correção dos sedimentos de dragagem, seriam necessários testes experimentais, bem como a aplicação de critérios de classificação do lodo e do resíduo a serem utilizados, além de critérios para avaliação e controle da qualidade físico química das misturas para uso posterior específico.

Quanto à dessalinização, o processo requer o cumprimento de etapas para eliminação do excesso de sais solúveis em água, cuja concentração é averiguada por meio da medição de condutividade elétrica. O Guia para Uso Benéfico de Material Dragado (BURT, 1996) traz as etapas a serem seguidas no processo de dessalinização.

As principais recomendações para uso de material dragado na agricultura são:

- Correção do sedimento para parâmetros necessários ao uso a que se destinará.

Para que a correção seja feita, é preciso que sejam conhecidas as características físico-químicas do solo ao qual será aplicado o sedimento, bem como as características físico-químicas e toxicológicas do sedimento dragado; e

- Segundo Harrington \& Smith (2013), a proporção ótima da mistura de material dragado grosso e fino com material orgânico deve ser determinado conforme as necessidades do solo a ser tratado.

Darmody \& Diaz, (2017) afirmam que alguns estudos em escala experimental têm sido feitos para se avaliar o potencial de correção de solos pobres com o uso de sedimentos de dragagem, enquanto que aplicações em campo são raras. A literatura apresenta inúmeras aplicações de sedimentos dragados ao solo advindos de obras 
de dragagem em lagos e rios, onde a salinidade não precisa ser abordada, e com composição granulométrica específica, diferente das normalmente encontradas em fundo marinho.

* Fasiver, Bélgica - 2007.

Uma área contaminada, de 42 ha foi transformada em um centro de tratamento de material dragado, além da remediação de 7 ha de área, que estavam contaminados. O local recebeu um projeto no qual 30 ha foram destinados a serem convertidos em área industrial, e $10 \mathrm{ha}$, em área verde. O lucro conseguido com a venda do terreno deve servir para cobrir os custos da remediação. A fase operacional foi iniciada em 2000, e ao final de 2007, 850 t de material dragado haviam sido tratados e utilizados no local. A Erro! Fonte de referência não encontrada.12, a seguir, ilustra o local.

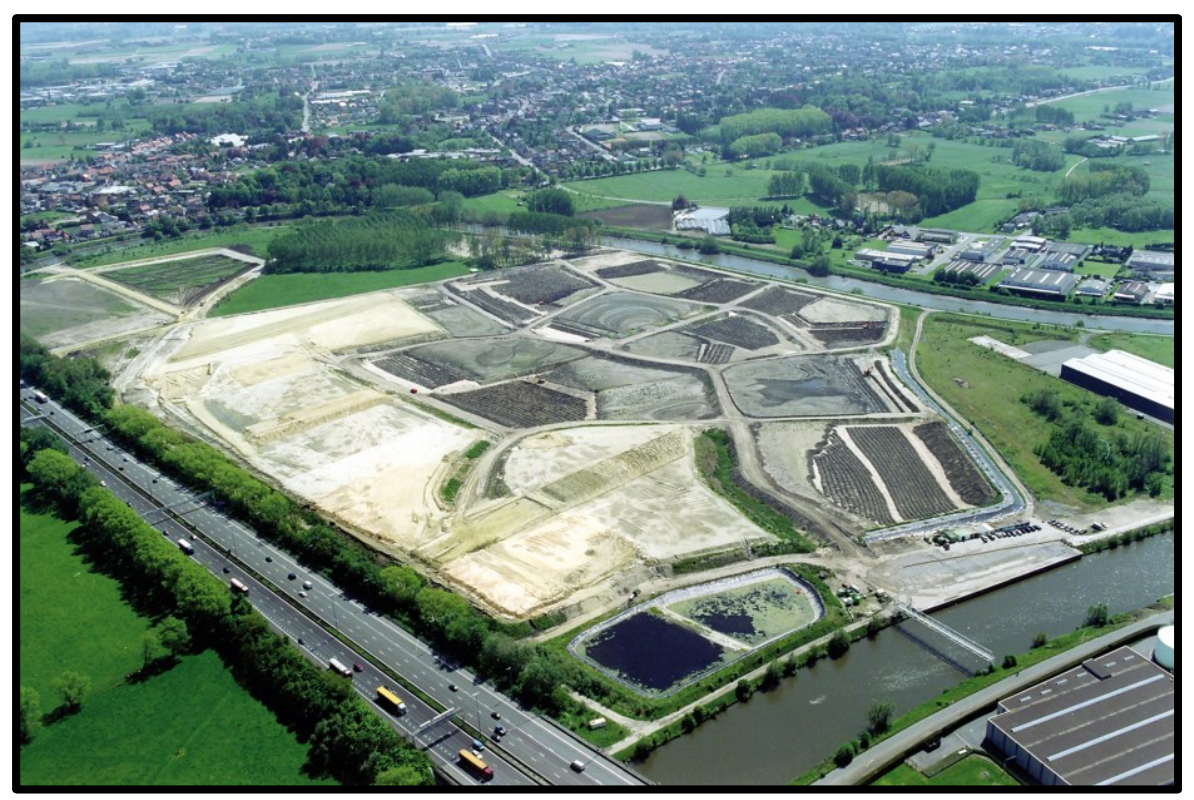

Figura 11: Vista panorâmica da área contaminada transformada em centro de tratamento de material dragado, em Fasiver, na Bélgia.

Fonte: Murray, 2008.

\section{* Vintondale, Pensilvânia (Estados Unidos) - 1990.}

Areia do município de Donora, e misturado a resíduos de fibra de papel, uma mistura de esterco bovino, cal, fertilizante e resíduo ácido de mineração. Com o produto final, 5.000 árvores e arbustos foram plantados em um terreno abandonado de uma mina de carvão, e o local transformado em um parque recreativo e de espécies silvestres para a comunidade de Vintondale. Em 2001, o mesmo processo foi realizado para utilização do solo na construção de um sistema tipo wetland. $\mathrm{E}$ em 2003, areia dragada de Donora foi misturada à resíduos de poda, esterco de aves, fertilizante e resíduo ácido de mineração. A mistura final foi usada na construção de um campo de futebol e um campo de baseball no parque. 


\section{CIDESPORT/2019}

\section{Congresso Internacional}

de Desempenho Portuário

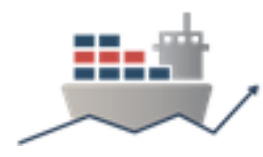

\section{DISCUSSÃO}

\subsection{Engordamento de praias}

A utilização de sedimentos para engordamento de praias e contenção de erosão é uma prática antiga e usual no Brasil, e há diversos casos de sucesso espalhados pelo país. Porém, percebe-se que a viabilidade do projeto depende da questão logística de se encontrarem regiões que precisem do material e que estejam relativamente próximas aos locais de dragagem. Por exemplo, Neto et al. (2017) afirmam que há a necessidade do engordamento de praias no litoral do estado do Paraná devido aos problemas de erosão costeira. Os mesmos autores destacam que a areia dragada no Canal da Galheta poderia ser usada na obra de recuperação costeira. Desta forma, conclui-se que há a necessidade de uma integração do plano da obra de dragagem com o plano de recuperação de áreas costeiras, a fim de avaliar os sítios dragados, a caracterização do sedimento e suas possíveis destinações para o seu aproveitamento, constituindo-se assim em uma solução menos custosas do que o descarte no oceano. A Tabela 1 traz as vantagens e desvantagens relacionadas a obras de proteção costeira.

Tabela 1: Vantagens e desvantagens de obras de proteção costeira.

\begin{tabular}{|l|l|}
\hline \multicolumn{1}{|c|}{ Vantagens } & \multicolumn{1}{|c|}{ Desvantagens } \\
\hline $\begin{array}{l}\text { Auxilia no controle de erosão costeira e na } \\
\text { prevenção de inundações. }\end{array}$ & $\begin{array}{l}\text { Demanda análise de engenharia detalhada para } \\
\text { avaliar com precisão o clima local (em termos de } \\
\text { ondas) e as taxas de erosão da praia. }\end{array}$ \\
\hline $\begin{array}{l}\text { Valoriza a área turística ao ampliar a faixa de } \\
\text { areia das praias. }\end{array}$ & $\begin{array}{l}\text { Caso o material utilizado no engordamento } \\
\text { apresente características diferentes (textura, cor, } \\
\text { dentre outros) aos sedimentos da praia natural in- } \\
\text { situ, a estética da mesma pode ser impactada } \\
\text { negativamente. }\end{array}$ \\
\hline $\begin{array}{l}\text { Solução eficiente e visualmente mais atrativa se } \\
\text { comparada à obras de engenharia como a } \\
\text { construção de vigas e esporões. }\end{array}$ & - \\
\hline
\end{tabular}

Fonte: Adaptado de Harrington \& Smith, 2013.

\subsection{Bermas onshore e offshore}

A Resolução CONAMA no 454/12, em seu Art. 15, cita em seu inciso $1^{\circ}$, que trata dos usos benéficos de material dragado, bermas offshore como alternativa de uso. No entanto, conforme mostrado no presente estudo, há outros tipos de bermas, que constituem alternativas factíveis a serem consideradas.

A CONAMA 420/09 que dispõe sobre critérios e valores orientadores de qualidade do solo quanto à presença de substâncias químicas e estabelece diretrizes para o gerenciamento ambiental de áreas contaminadas por essas substâncias em decorrência de atividades antrópicas. No Art. 15 desta Resolução, determina-se que o nível de concentração de contaminantes para uso não ultrapasse limites dos valores de proteção ambiental (RESOLUÇÃO CONAMA No 420, 2009). A Tabela 2 lista vantagens e desvantagens relacionadas à implementação de Bermas. 
Tabela 2: Vantagens e desvantagens da aplicação de bermas

\begin{tabular}{|l|l|}
\hline \multicolumn{1}{|c|}{ Vantagens } & \multicolumn{1}{c|}{ Desvantagens } \\
\hline $\begin{array}{l}\text { Pode ser criada pela simples descarga de material } \\
\text { dragado, usando-se dragas hopper. }\end{array}$ & $\begin{array}{l}\text { Bermas offshore criadas para serem estáveis } \\
\text { podem estar susceptíveis à erosão em função da } \\
\text { taxa de erosão no clima local de ondas. }\end{array}$ \\
\hline $\begin{array}{l}\text { Local da dragagem e local de aplicação podem } \\
\text { ser próximos para reduzir custos com transporte. }\end{array}$ & $\begin{array}{l}\text { Pode não ser apropriado para locais que haja } \\
\text { conflitos de uso com pescadores, portos e } \\
\text { emissários submarinos. }\end{array}$ \\
\hline $\begin{array}{l}\text { Pode ser uma solução para proteção costeira, } \\
\text { considerada de "engenharia leve", } \\
\text { ambientalmente aceitável. }\end{array}$ & $\begin{array}{l}\text { Local ótimo de deposição dos sedimentos deve } \\
\text { ser de uma profundidade tal que o uso da técnica } \\
\text { possa mitigar os efeitos das ondas. }\end{array}$ \\
\hline
\end{tabular}

Fonte: Adaptado de Harrington \& Smith, 2013.

\subsection{Aterros Hidráulicos}

O Brasil possui diversos casos de sucesso na aplicação de sedimentos dragados para aterramento hidráulico de novas áreas, tais como a expansão do aeroporto internacional do Galeão - RJ, realizada em 1973 com argila dragada da baía de Guanabara por meio de dragas de sucção e recalque, o Monumento dos Pracinhas no aterro do Flamengo - RJ em 1950, entre outros.

A técnica de aterramento não é de alta complexidade, porém requer estudos prévios da área e dos sedimentos para que haja compatibilidade entre a destinação dos sedimentos e sua função no meio (preenchimento do terreno ou como base para alguma infraestrutura). Sedimentos mais arenosos podem ser facilmente destinados para aplicação em terrenos (sem construção) visando o aterramento ou a recuperação do solo local. Um bom exemplo é a utilização de areias dragadas para preenchimento em áreas públicas, tais como parques e áreas recreacionais. A utilização de argilas e materiais "pastosos", apesar de viável, pode encontrar barreiras econômicas e de aceitação devido à necessidade de tratamento (secagem e mistura com areia, cal, cimentos, entre outros). A Tabela 3 , a seguir, lista algumas vantagens e desvantagens das obras de aterros com uso de material dragado.

Tabela 3: Vantagens e desvantagens de aterros hidráulicos.

\begin{tabular}{|l|l|}
\hline \multicolumn{1}{|c|}{ Vantagens } & \multicolumn{1}{c|}{ Desvantagens } \\
\hline $\begin{array}{l}\text { Melhoria estética e de aproveitamento do espaço } \\
\text { (novas áreas recreacionais). }\end{array}$ & $\begin{array}{l}\text { Níveis de contaminação dos sedimentos } \\
\text { dragados devem estar em nível adequado para o } \\
\text { uso pretendido dos materiais. }\end{array}$ \\
\hline $\begin{array}{l}\text { Melhorias ambientais provenientes do plantio de } \\
\text { flora local em áreas aterradas. }\end{array}$ & $\begin{array}{l}\text { A dessalinização do material dragado se faz } \\
\text { necessária caso a área aterrada seja destinada } \\
\text { para o plantio de árvores. }\end{array}$ \\
\hline Valorização da região nos entornos. & $\begin{array}{l}\text { A desidratação do material dragado é geralmente } \\
\text { necessária, agregando custos ao processo de } \\
\text { aterramento. }\end{array}$ \\
\hline
\end{tabular}

Fonte: Adaptado de Harrington \& Smith, 2013. 


\section{CIDESPORT/2019}

\section{Congresso Internacional}

de Desempenho Portuário

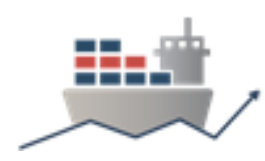

\subsection{Blocos e tijolos}

Esta opção de aproveitamento apresenta elevado potencial de aplicação, tendo em vista a tendência mundial de utilização de materiais sustentáveis na construção civil. Cappuyns et al. (2015) realizaram uma pesquisa sobre a percepção das pessoas e valorização dos blocos feitos de materiais dragados em Flanders, Bélgica. Percebeu-se que há certa resistência por parte da população na utilização dos blocos (oriundos de material dragado) na construção civil, seja por falta de conhecimento, seja pelo medo em adquirir produtos com qualidade inferior ou contaminados.

Referente a qualidade dos blocos, Hamer \& Karius (2002) afirmam que os tijolos produzidos a partir de sedimentos contaminados possuem boa qualidade para aplicação na indústria, superam em desempenho algumas características mecânicas de tijolos tradicionais e imobilizam substâncias tóxicas como metais pesados.

No caso brasileiro, considerando-se o tipo de construção predominante (alvenaria), recomenda-se a realização de estudos técnicos e econômicos para verificar a viabilidade desta forma de aproveitamento (tijolos ou pavimento). Ressaltase a importância da proximidade da indústria de produção de blocos e tijolos com os locais de dragagem, de modo a minimizar os custos logísticos e tornar o empreendimento viável. A Tabela traz algumas vantagens e desvantagens relacionadas ao uso de material dragado para produção de blocos e tijolos.

Tabela 4: Vantagens e desvantagens do uso de material dragado em tijolos e blocos.

\begin{tabular}{|l|l|}
\hline \multicolumn{1}{|c|}{ Vantagens } & \multicolumn{1}{c|}{ Desvantagens } \\
\hline $\begin{array}{l}\text { Aproveitamento de sedimentos contaminados e } \\
\text { neutralização de substâncias tóxicas. }\end{array}$ & $\begin{array}{l}\text { Características e consistência para produção de } \\
\text { tijolos devem ser atendidas. }\end{array}$ \\
\hline $\begin{array}{l}\text { Valorização econômica do sedimento (insumo } \\
\text { para indústria) e oportunidade de geração de } \\
\text { renda. }\end{array}$ & $\begin{array}{l}\text { Poucas plantas operando no mundo e } \\
\text { normalmente com pequena/média escala. }\end{array}$ \\
\hline
\end{tabular}

Fonte: Adaptado de Harrington \& Smith, 2013.

\subsection{Aterro para base de estradas e superfícies pavimentadas}

Do ponto de vista técnico, existe grande viabilidade de implementar esse tipo de destinação para os sedimentos marinhos dragados nos portos brasileiros, conforme apontado pelo estudo realizado por Mymrin et al. (2016).

Alguns aspectos logísticos devem ser apurados, primeiramente na armazenagem do material dragado, pois o volume de sedimento dragado é considerável e necessita de grandes áreas. Custos logísticos devem ser contabilizados levando-se em consideração o transporte para disposição final nos oceanos. Estes podem ser mais elevados do que armazenamento em terra, demandando, portanto, uma análise caso a caso mais criteriosa.

A mesma técnica de aproveitamento pode ser utilizada para outros tipos de fundação, desde que haja prévia investigação das propriedades mecânicas do solo local e do sedimento dragado a ser aproveitado.

Destaca-se que as principais dificuldades para utilização de material dragado na construção civil, sejam estas o alto teor de água, a salinidade ou a matéria orgânica, quando combinados, proporcionam baixas características mecânicas ao material, necessitando assim de tratamento prévio para seu aproveitamento. Assim, o tratamento consiste na desidratação, retirada da salinidade e mistura com outros agregados (areia, cimento, cal, cinzas e outros) para melhorar as características 


\section{CIDESPORT/2019}

\section{Congresso Internacional}

de Desempenho Portuário

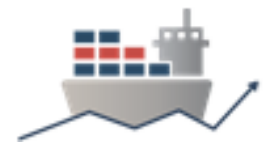

mecânicas do composto a ser usado como aterro. A seguir, a Tabela lista vantagens e desvantagens do uso de aterros para base de estradas e superfícies pavimentadas.

Tabela 5: Vantagens e desvantagens de aterros para base de superfícies pavimentadas.

\begin{tabular}{|l|l|}
\hline \multicolumn{1}{|c|}{ Vantagens } & \multicolumn{1}{c|}{ Desvantagens } \\
\hline $\begin{array}{l}\text { Opção de uso em várias camadas do aterro ou } \\
\text { outros tipos de fundação. }\end{array}$ & $\begin{array}{l}\text { Necessidade de tratamento e mistura com outros } \\
\text { materiais (pode inviabilizar financeiramente o } \\
\text { sedimento). }\end{array}$ \\
\hline $\begin{array}{l}\text { Sedimentos contaminados podem ser usados, } \\
\text { pois ficarão confinados abaixo do pavimento. }\end{array}$ & $\begin{array}{l}\text { O uso de materiais finos está ainda em processo } \\
\text { de pesquisa e pouco aplicados no mundo. }\end{array}$ \\
\hline $\begin{array}{l}\text { Minimiza a exploração de recursos naturais em } \\
\text { pedreiras e minas. }\end{array}$ & $\begin{array}{l}\text { Custos com transporte podem inviabilizar uso em } \\
\text { áreas não costeiras. }\end{array}$ \\
\hline
\end{tabular}

Fonte: Adaptado de Harrington \& Smith, 2013.

\subsection{Agricultura}

Há vasta literatura relacionada à utilização de sedimentos de dragagem de rios e lagos na correção de solo com vistas a melhorias na agricultura. Sedimentos cuja origem está associada à água doce apresentam maior conteúdo de matéria orgânica, e, por esta razão, podem apresentar maior índice de contaminação. Em contrapartida, não havendo contaminação, estes sedimentos constituem matéria rica em composição orgânica para o enriquecimento de solos deficientes.

Os sedimentos advindos de dragagem marítima são constituídos de material arenoso e de baixo teor de matéria orgânica. Além disso, apresentam alto teor de sal, que deve ser eliminado por meio da dessalinização para, posteriormente, serem destinados à aplicação em solo cultivável. Pouco há na literatura que explore este tipo de aproveitamento, e mais aplicações experimentais são recomendadas, tanto no que diz respeito à dessalinização, como no aproveitamento de resíduos variados para o enriquecimento orgânico e estabilização da composição do sedimento dragado.A

Tabela 6 traz algumas vantagens e desvantagens relacionadas ao uso de material dragado na recomposição de solos, ou seja, agricultura.

Tabela 6: Vantagens e desvantagens do uso de material dragado na agricultura.

\begin{tabular}{|l|l|}
\hline \multicolumn{1}{|c|}{ Vantagens } & \multicolumn{1}{|c|}{ Desvantagens } \\
\hline $\begin{array}{l}\text { Pode ser uma fonte de renda para os portos que } \\
\text { produzirem quantidades significativas de material } \\
\text { dragado de dragagens de manutenção } \\
\text { periodicamente. }\end{array}$ & $\begin{array}{l}\text { Dependência da demanda de mercado próximo } \\
\text { às áse geração de material dragado. }\end{array}$ \\
\hline $\begin{array}{l}\text { Pesquisas significativas têm sido realizadas com } \\
\text { diversos projetos finalizados nos Estados Unidos } \\
\text { e Reino Unido. }\end{array}$ & $\begin{array}{l}\text { As características do material dragado seguem } \\
\text { requisitos rigorosos. }\end{array}$ \\
\hline $\begin{array}{l}\text { Potencial para contribuir com a redução de custos } \\
\text { do município relacionados à disposição de } \\
\text { material na medida em que for usado com material } \\
\text { dragado na composição de solos. }\end{array}$ & $\begin{array}{l}\text { O material orgânico adequado deve ser de fonte } \\
\text { confiável e de forma regular. }\end{array}$ \\
\hline
\end{tabular}

Fonte: Adaptado de Harrington \& Smith, 2013. 
VI CIDESPORT/2019

Congresso Internacional

de Desempenho Portuário

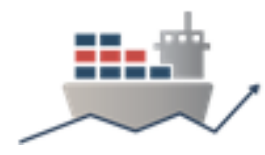

\section{ANÁLISE CRÍTICA}

Em complemento aos critérios, estudos de caso e análises críticas das possibilidades de aproveitamento do material dragado supracitados, a Tabela 7 apresenta informações referentes à adequação dos sedimentos dragados ao tipo de aproveitamento indicado, baseando-se em suas características físico-químicas.

Tabela 0: Adequação do Sedimento Dragado ao tipo de aproveitamento indicado.

\begin{tabular}{|c|c|c|c|c|c|c|c|c|c|c|c|}
\hline & \multicolumn{10}{|c|}{$\begin{array}{l}\text { Adequação do Sedimento Dragado baseado em suas } \\
\text { características físico-químicas }\end{array}$} \\
\hline $\begin{array}{l}\text { Categoria do } \\
\text { aproveitamento }\end{array}$ & $\begin{array}{l}\text { Tipo de } \\
\text { Aproveitamento }\end{array}$ & 은 & 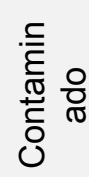 & D & 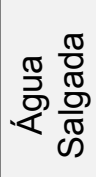 & $\frac{\pi}{\bar{\sigma}}$ & 离 $\frac{\pi}{\overline{0}}$ & $\frac{1}{0}$ & 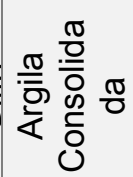 & 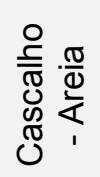 & \begin{tabular}{l}
$\frac{\pi}{0}$ \\
$\frac{0}{0}$ \\
\hdashline
\end{tabular} \\
\hline \multirow{5}{*}{$\begin{array}{l}\text { Obras de } \\
\text { engenharia }\end{array}$} & $\begin{array}{l}\text { Proteção } \\
\text { costeira }\end{array}$ & $\checkmark$ & $\checkmark$ & $\checkmark$ & $\checkmark$ & $x$ & $x$ & $\checkmark$ & $\checkmark$ & $\checkmark$ & $\checkmark$ \\
\hline & $\begin{array}{l}\text { Engordamento } \\
\text { de praia }\end{array}$ & $\checkmark$ & $\mathrm{x}$ & $\checkmark$ & $\checkmark$ & $x$ & $X$ & $x$ & $x$ & $\checkmark$ & -- \\
\hline & $\begin{array}{l}\text { Estabilização } \\
\text { da linha } \\
\text { margens de } \\
\text { rios e controle } \\
\text { de erosão }\end{array}$ & $\checkmark$ & -- & $\checkmark$ & $\checkmark$ & $\checkmark$ & -- & $\checkmark$ & $\checkmark$ & $\checkmark$ & $\checkmark$ \\
\hline & $\begin{array}{l}\text { Bermas } \\
\text { emersas }\end{array}$ & $\checkmark$ & $\mathrm{x}$ & $\checkmark$ & $\checkmark$ & $\checkmark$ & $\checkmark$ & $\checkmark$ & -- & $\checkmark$ & $x$ \\
\hline & $\begin{array}{l}\text { Bermas } \\
\text { submersas }\end{array}$ & $\checkmark$ & $\mathrm{x}$ & $\checkmark$ & $\checkmark$ & $\checkmark$ & $\checkmark$ & $\checkmark$ & $\checkmark$ & $\checkmark$ & $\checkmark$ \\
\hline \multirow{4}{*}{$\begin{array}{l}\text { Construção } \\
\text { civil e indústria }\end{array}$} & Aterro & $\checkmark$ & -- & $\checkmark$ & $\checkmark$ & $\checkmark$ & $\checkmark$ & $\checkmark$ & $x$ & $x$ & $x$ \\
\hline & Blocos e tijolos & $\checkmark$ & $\checkmark$ & $\checkmark$ & $\checkmark$ & $\checkmark$ & $x$ & $\checkmark$ & $\checkmark$ & $x$ & $x$ \\
\hline & $\begin{array}{l}\text { Aterro para } \\
\text { base de } \\
\text { estradas e } \\
\text { superfícies } \\
\text { pavimentadas }\end{array}$ & $\checkmark$ & $\checkmark$ & $\checkmark$ & $x$ & $x$ & -- & $\checkmark$ & $\checkmark$ & $\checkmark$ & $\mathrm{x}$ \\
\hline & Agricultura & $\checkmark$ & -- & $x$ & $\checkmark$ & $\checkmark$ & $\checkmark$ & $\checkmark$ & $x$ & $x$ & $x$ \\
\hline
\end{tabular}

$\mathbf{X}$ : Inadequado; --: Parcialmente Adequado; $\mathbf{V}$ : Adequado.

Fonte: Adaptado de HARRINGTON \& SMITH, 2013.

A partir dos dados adquiridos por meio da revisão de literatura, foi desenvolvida a Tabela 0 , que apresenta aspectos dos tipos de aproveitamento e suas aplicabilidades no contexto brasileiro. Para tal, foram considerados critérios de ponderação referentes aos seguintes aspectos:

- Explorado no Brasil - número de aplicações em escala experimental ou real;

- Custos - Valor associado à aplicação da técnica;

- Legislação ambiental - Restrições legais à aplicação da técnica;

- Logística - Número de pessoas por processos, equipamentos e distância;

- Tecnologia - Grau de complexidade associado à técnica; e

- Pessoal - Exigência de qualificação. 


\section{CIDESPORT/2019}

\section{Congresso Internacional}

de Desempenho Portuário

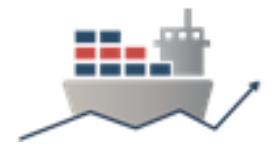

Tabela 0: Aspectos inerentes ao tipo de aproveitamento e sua aplicabilidade no Brasil.

\begin{tabular}{|c|c|c|c|c|c|c|}
\hline \multirow{2}{*}{$\begin{array}{c}\text { TIPO DE } \\
\text { APROVEITAMENTO }\end{array}$} & \multicolumn{6}{|c|}{ ASPECTOS } \\
\hline & $\begin{array}{l}\text { Explorado } \\
\text { no brasil }\end{array}$ & Custos & $\begin{array}{l}\text { Legislação } \\
\text { ambiental }\end{array}$ & Logística & Tecnologia & Pessoal \\
\hline $\begin{array}{l}\text { Engordamento de } \\
\text { praias }\end{array}$ & +++ & ++ & +++ & ++ & +++ & +++ \\
\hline Aterro hidráulico & +++ & ++ & +++ & ++ & ++ & ++ \\
\hline $\begin{array}{l}\text { Disposição nos } \\
\text { oceanos }\end{array}$ & +++ & +++ & +++ & +++ & +++ & +++ \\
\hline Blocos/tijolos & - & + & ++ & + & + & + \\
\hline Bermas & - & ++ & ++ & + & + & ++ \\
\hline Agricultura & - & ++ & +++ & + & + & + \\
\hline $\begin{array}{ll}\text { Aterro } & \text { para } \\
\text { pavimento } & \end{array}$ & - & ++ & +++ & ++ & ++ & ++ \\
\hline $\begin{array}{ll}\text { Preenchimento } & \text { de } \\
\text { terrenos (aterro) } & \end{array}$ & +++ & + & +++ & ++ & ++ & ++ \\
\hline \multicolumn{7}{|c|}{ Critérios de Ponderação: } \\
\hline \multicolumn{7}{|c|}{ Não encontrado } \\
\hline \multicolumn{7}{|c|}{ Baixo } \\
\hline \multicolumn{7}{|l|}{ Médio } \\
\hline \multicolumn{7}{|l|}{ Alto } \\
\hline
\end{tabular}

Fonte: Adaptado de Harrignton \& Smith, 2013.

Nesta análise, são apresentadas alternativas de aproveitamento de material dragado e suas respectivas viabilidades de implementação no âmbito brasileiro. Notase que o uso de sedimentos de dragagem para fins de destinação como engordamento de praias, aterramento hidráulico de terreno e destinação oceânica são práticas usuais em todos os aspectos apresentados pela Tabela 0. 
VI CIDESPORT/2019

Congresso Internacional

de Desempenho Portuário

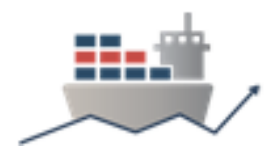
decisão

Mediante todo processo de pesquisa realizado, é apresentada a árvore de

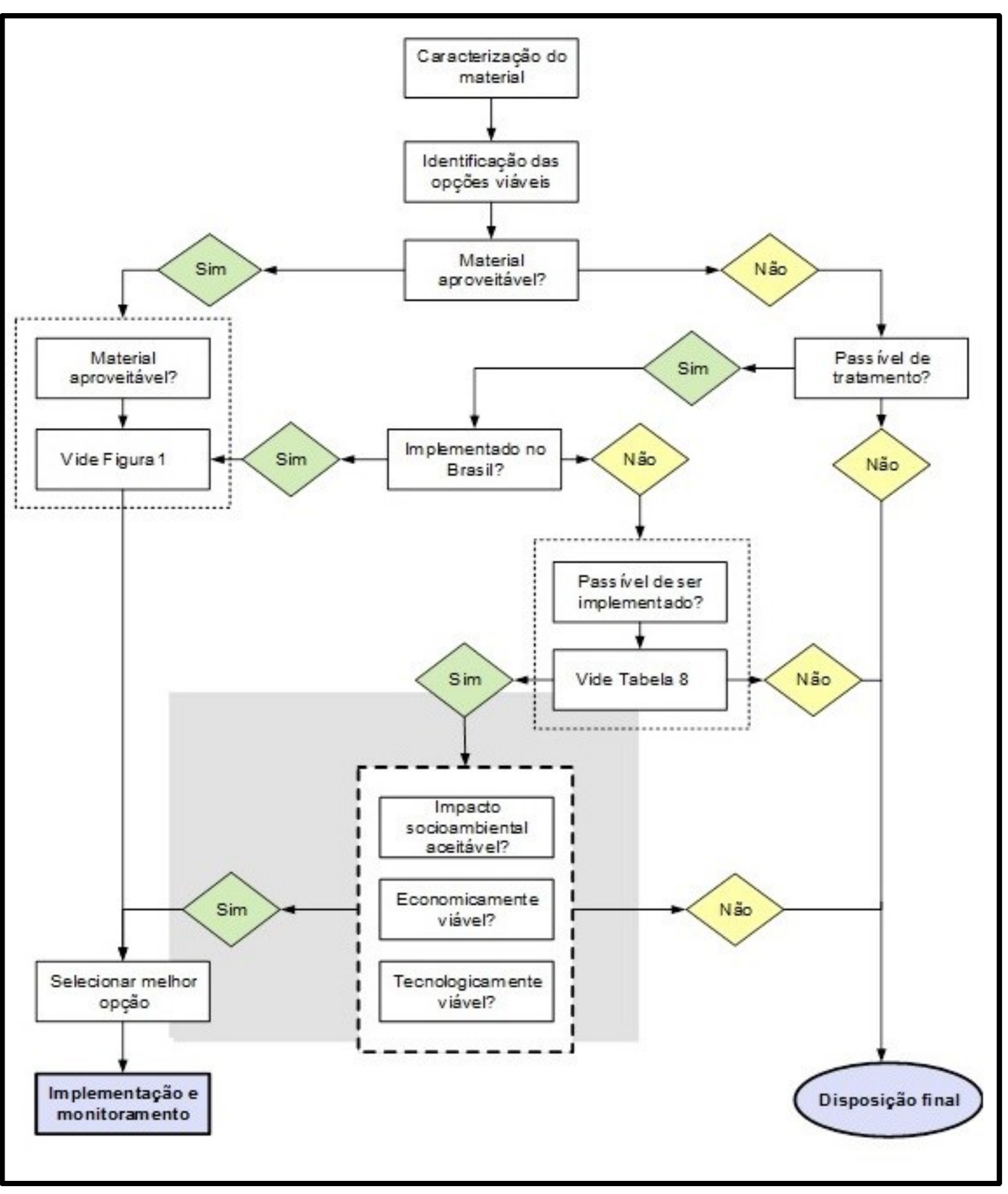

13), que traz, de forma concisa e direta o conteúdo elaborado neste documento. Com esta árvore de decisão, almeja-se subsidiar a tomada de decisão do gestor público quanto ao uso de material dragado proveniente de obras nos canais de acesso aos portos brasileiros, por meio de soluções técnico-econômicas e ambientais viáveis. 
VI CIDESPORT/2019

Congresso Internacional

de Desempenho Portuário

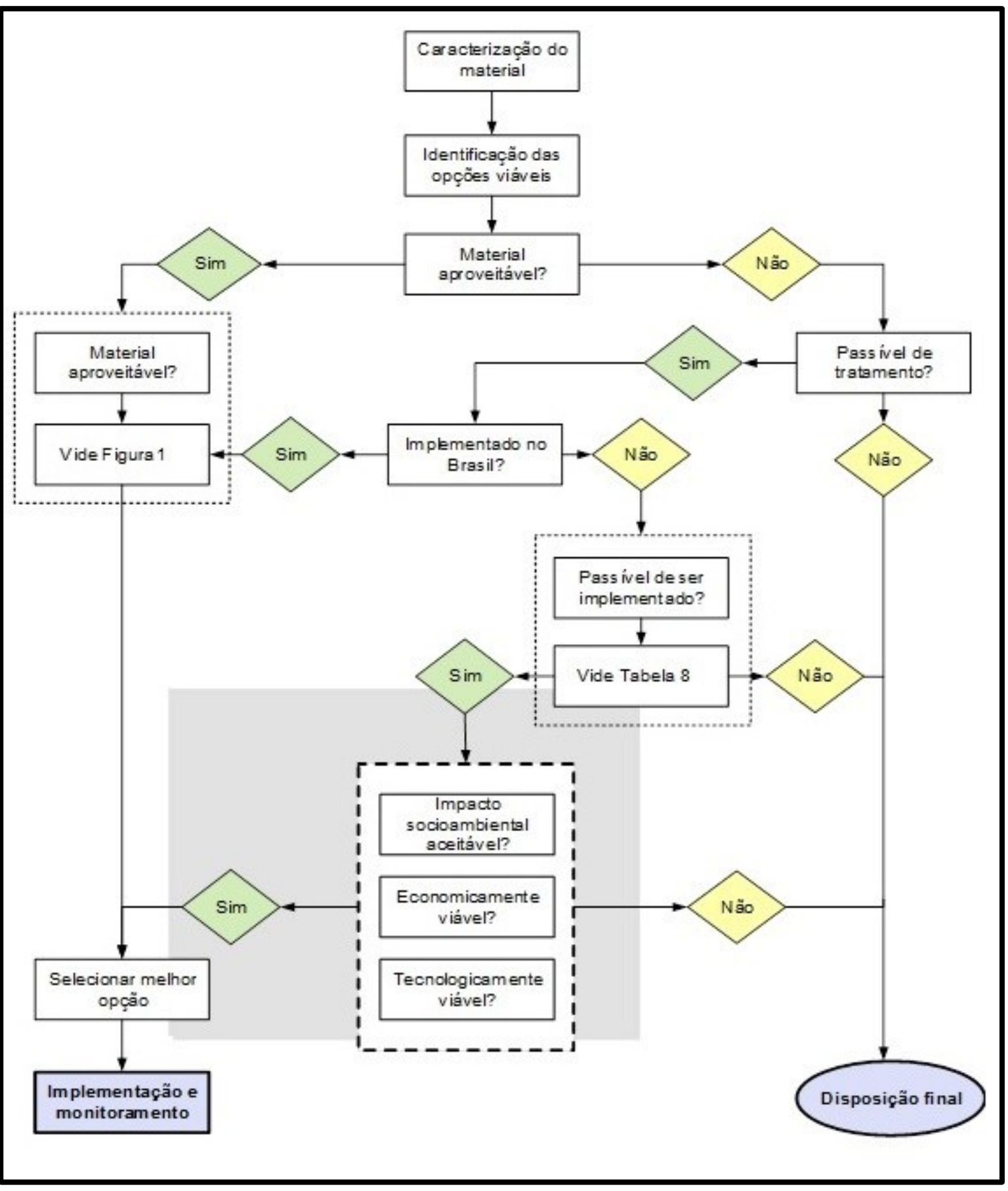

Figura 12: Árvore de decisão para uso do sedimento dragado.

Fonte: Elaboração própria.

\section{CONCLUSÕES}

No cenário mundial, as pesquisas apontam avanço na viabilidade econômica, ambiental e social do aproveitamento de sedimentos dragados. Neste contexto, esta pesquisa, embasada na literatura e estudo de casos nacionais e internacionais, considera que a simples disposição final dos sedimentos nos oceanos constitui em perda de oportunidade para a geração de valor e de renda local.

Em contrapartida, optar pelo aproveitamento do material auxilia na mitigação dos impactos ambientais relacionados, maximizando, portanto, os benefícios à 


\section{CIDESPORT/2019}

Congresso Internacional

de Desempenho Portuário

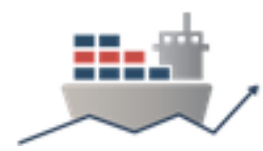

sociedade e ao meio ambiente. Questões como a contabilização dos custos logísticos, além de aspectos sociais, legais, estratégicos e ambientais devem ser considerados pelo gestor público.

Historicamente, o engordamento artificial de praias e aterramentos hidráulicos foram amplamente explorados entre 1969 e 1982, tomando-se como exemplo a cidade do Rio de Janeiro. Estas técnicas podem ser aplicadas em outras localidades brasileiras, mas, conforme pesquisa realizada neste documento, há outras possibilidades de aproveitamento a serem consideradas.

A análise crítica apresentada, constituída por tabelas sínteses e uma árvore de decisão, possibilitará embasar o gestor público em sua tomada de decisão quanto às formas mais adequadas e sustentáveis de aproveitamento do material dragado durante obras de dragagem nos portos brasileiros.

Como recomendação final, propõe-se a formulação de um plano de viabilidade associado ao Programa Nacional de Dragagem - PND para sugerir caminhos e alternativas de aproveitamento do material dragado, com potencial de gerar renda $\mathrm{e}$ contribuir para a gestão ambiental adequada nos portos brasileiros em longo prazo.

\section{REFERÊNCIAS}

ARAÚJO, H. M. M. 2012. Museu da Maré: entre educação, memórias e identidades. Tese de Doutorado, Programa de Pós-Graduação em Educação. Rio de Janeiro: PUC-Rio. Disponível em: <https://www.maxwell.vrac.pucrio.br/21758/21758_6.PDF>. Acesso em 18 set. 2018.

ASON, B.; ABABIO, F. O.; BOATENG, E.; YANGYUORU, M. 2015. Comparative Growth Response of Maize on Amended Sediment from the Odaw River and Cultivated Soil. World Journal of Agricultural Research, 3(4): 143-147.

BARNARD, P. L.; ERIKSON, L. H.; HANSEN, J. E.; ELIAS, E. The Performance of Nearshore Dredge Disposal at Ocean Beach, San Francisco, California, 2005-2007. U.S. Department of the Interior. U.S. Geological Survey, Reston, Virginia 2009.

BRASIL. 2010. Política Nacional de Resíduos Sólidos (Lei 12.305/2010)

BRUTSCHÉ, K. E.; WANG, P.; ROSATI, J. D.; POLLOCK, C. E. Engineering with Nature: Nearshore Berm Placements at Fort Myers Beach and Perdido Key, Florida, USA. Coastal Sediments, 2015.

BURT, T. N. 1996. Guidelines for the beneficial use of dredged material. Report SR488, HR Wallingford. $111 \mathrm{p}$.

CAPPUYNS, V.; DEWEIRT, V.; ROUSSEAU, S. 2015. Dredged sediments as a resource for brick production: Possibilities and barriers from a consumers' perspective. Waste Management, 38: 372-380.

CEDA - Central Dredging Association. 2010. Dredged Material as a Resource: Options and Constraints. A CEDA Information Paper - June 2010. Delft, 3 p. Disponível em: <https://dredging.org/documents/ceda/downloads/publications-20106-ceda_information-paper-dredgedmaterialasaresource.pdf $>$. 


\section{CIDESPORT/2019}

\section{Congresso Internacional}

de Desempenho Portuário

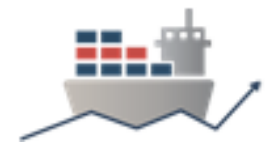

CONCEIÇÃO, R. A. A. 2016. Gestão de dragagens portuárias - alguns aspectos geotécnicos e geoambientais. Dissertação para obtenção do Grau de Mestre em Engenharia Geológica. Faculdade de Ciências e Tecnologia. Universidade Nova de Lisboa.

CPGG, 2018. Laboratório de Estudos Costeiros Instituto de Geociências - UFBA Campus Ondina - Salvador - Bahia. Disponível

em:<http://www.cpgg.ufba.br/lec/BEeros.htm>. Acessado em agosto de 2018.

DARMODY, R. G. \& DIAZ D. R. 2017. Dredged Sediment: Application as an Agricultural Amendment on Sandy Soils. Illinois Sustainable Technology Center. Prairie Research Institute. University of Illinois at Urbana-Champaign. Disponivel em: <https://www.istc.illinois.edu/UserFiles/Servers/Server_427403/File/TR066.pdf> Acesso em: 11/09/2018.

DREDGEPOINT, 2018. Gosho. Disponível em:

<https://www.dredgepoint.org/dredging- database/equipment/gosho>. Acesso em: 04 set. 2018.

EAEMÁQUINAS, 2016. SUL DRAGAS: referência em soluções para dragagem. Disponível em: <https://www.eaemaquinas.com.br/products/sul-dragas-referenciaem-solucoes- para-dragagem/>. Acesso em: 04 set. 2018.

ENVIRONTOOLS, 2018. Disponível em: <

http://www.envirotools.msu.edu/about.shtml>. Acesso em: 04 out. 2018.

ESCOLA POLITÉCNICA UFRJ, 2012. Será inaugurada amanhã a Ponte do Saber. Disponível em: < http://www.poli.ufrj.br/noticias/noticias.php?numnews=826>. Acesso em: 27 out. 2018.

GEOPRISMA, 2017. As Ilhas Artificiais de Dubai. Disponível em:< http://www.geoprisma.com.br/noticias/47/as-ilhas-artificiais-de-dubai/>. Acesso em: outubro de 2018.

GUPTA, S. C.; LARSON, W. E.; GAST, R. G.; COMBS, S. M.; DOWDY, R. H. 1978. The Agricultural Value of Dredged Material. Army Engineer Waterways Experiment Station Vicksburg Miss. Defense Technical Information Center. Disponível em: <http://www.dtic.mil/dtic/tr/fulltext/u2/a061298.pdf>. Acesso em 10 set. 2018.

HARRINGTON, J.; SMITH, G. 2013. Guidance on the Beneficial Use of Dredge Material in Ireland. School of Building \& Civil Engineering Cork Institute of Technology. Environmental Protection Agency. Ireland, 2013. Disponível em: < https://www.epa.ie/pubs/reports/research/sss/Beneficial\%20Use\%20of\%20Dredging $\% 20$ Material.pdf>. Acesso em 10 set. 2018.

INEA - Instituto Estadual do Meio Ambiente. 2012. Ambiente do Rio. Rio de Janeiro: SEA, $72 \mathrm{p}$.

JAGLAL, K. K.; CRAWFORD, D. M.; ANAGNOST, S. W. \& WHITE, B. E. 2017. Alternative approaches for managing dredged sediment. Dredging Summit \& EXPO, 
VI CIDESPORT/2019

Congresso Internacional

de Desempenho Portuário

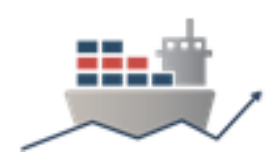

Vancouver.

JONES, C. 2017. História do 'Projeto Rio' na Maré Parte 1: O Canto da Sereia.

RioOnWatch. Disponível em <http://rioonwatch.org.br/?p=26789>. Acesso em 18 set. 2018.

LYRA, M. 2012. Erosão Costeira Solução e Estudo e Planejamento. Disponível em: < http://marcolyra.blogspot.com/2012/07/12-pontos-onde-o-calcadao-deponta.html\%20e\%20https://correio9.com.br/erosao-costeira-solucao-e-estudo-eplanejamento/. >. Acesso em 27 nov. 2018.

MARYLAND DEPARTMENT OF ENVIRONMENT. Innovative Reuse and Beneficial Use of Dredged Material. Guidance Document. 2017.

MEZENCEVOVA, A.; YEBOAH, N.; BURNS, S.; KAHN, L.; KURTIS, K. 2012. Utilization of Savannah Harbor river sediment as the primary raw material in production of fired brick.

MURRAY, L. A. 2008. Dredged Material as a Resource. Terra et Aqua, 112: XX-XX.

MUSEU DA MARÉ, 2010. História da Maré II - de 1940 aos dias de hoje. 1983 - A Vila do Pinheiro. O Aterro da Ilha do Pinheiro. Disponível em:

$<$ http://www.museudamare.org.br/index.php?option=com_content\&view=article\&id=1 $37 \&$ Itemid=159>. Acesso em 18 set. 2018.

OLIVEIRA, J. F., 2012. Identificação de áreas de sedimentos compatíveis na plataforma continental interna para recuperação de praias entre as cidades de Niterói e Macaé - RJ. Dissertação de Mestrado, Programa de Pós-Graduação em Geociências. Universidade Federal do Rio Grande do Sul. Porto Alegre. Disponível em: <

https://www.lume.ufrgs.br/bitstream/handle/10183/56334/000860714.pdf?sequence= 1>. Acesso em Agosto de 2018.

PIANC. 1992. Beneficial use of dredged material. Disponível em: < https://www.iadcdredging.com/ul/cms/terraetaqua/document/1/3/0/130/130/1/terra-et-aqua-nr9201.pdf>. Acesso em: 13 out. 2018.

RESOLUÇÃO CONAMA N 420, de 28 de dezembro de 2009. Disponível em: < http://www2.mma.gov.br/port/conama/legiabre.cfm?codlegi=620>. Acesso em: 25 set. 2018.

SAID, I.; MARWA, Z.; MISSAOUI, A.; ZOUBEIR, L.; ESSAIEB, H. 2017. Dredged marine sediment as raw material in civil engineering applications. International Congress and Exhibition "Sustainable Civil Infrastructures: Innovative Infrastructure Geotechnology". Disponível em: <https://link.springer.com/chapter/10.1007\%2F9783-319-61612-4_33>. Acesso em: 02 set. 2018.

US ARMY ENGINEER WATERWAYS. Interim Design Guidance for Nearshore Berm Construction. Dredging Research Technical Notes, 1990. 
VI CIDESPORT/2019

Congresso Internacional

de Desempenho Portuário

VELLINGA, T.; EISMA, M. (2005). Management of contaminated dredged material in the port of Rotterdam. In: Vermaat J., Salomons W., Bouwer L., Turner K. (eds) Managing European Coasts. Environmental Science. Springer, Berlin, Heidelberg

VLASBOM, W. J. 2007. Chapter 2: Trailing suction hopper dredger. In: Designing Dredging Equipment. Disponível em: <https://www.dredging.org/documents/ceda/ downloads/vlasblom2-trailing_suction_hopper_dredger.pdf>. Acesso em: 04 set. 2018.

VLASBOM, W. J. 2007. Chapter 8: The backhoe or Dipper dredger. In: Designing Dredging Equipment. Disponível em:

$<$ https://dredging.org/media/ceda/org/documents/ resources/othersonline/vlasblom8the-backhoe-or-dipper-dredger.pdf>. Acesso em: 04 set. 2018.

WITZGALL, J. Jetty Island Management Plan. Port of Everett, 2006.

ZENTAR, R.; WANG, D.; ABRIAK, N. 2013. Strength and deformation properties of Dunkirk marine sediments solidified with cement, lime and fly ash. Engineering Geology. DOI: 10.1016/j.enggeo.2013.09.007 